\title{
Florestas secundárias do Parque Estadual da Cantareira, São Paulo, SP, Brasil: Variações florísticas e estruturais ${ }^{1}$
}

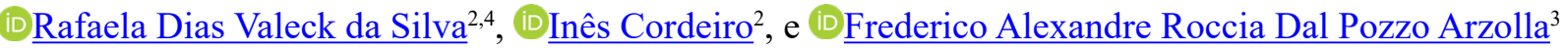

How to cite: Silva, R.D.V., Cordeiro, I., Arzolla, F.A.R.D.P. 2022. Florestas secundárias do Parque Estadual da Cantareira, São Paulo, SP, Brasil: Variações florísticas e estruturais. Hoehnea 49: e1082020. https://doi.org/10.1590/2236-8906-108/2020

\begin{abstract}
Secondary forests of the Parque Estadual da Cantareira, São Paulo State, SP, Brasil: Floristic and structural variations). The Parque Estadual da Cantareira, in the Atlantic Forest biome, was created from the expropriation of coffee farms for the protection of water sources for São Paulo city in 1877. Since then, few human activities have taken place in its interior. Here, we compare the composition and the successional stages of different fragments of near forests $(<0.5 \mathrm{~km}$ of each other); 0.6 ha were raised, divided in three areas of 0.2 ha each, with trees reaching PAP $\geq 15 \mathrm{~cm}$, being sampled, identified and measured for diameter and height. The succession stage of the species was determined and a profile of each area was drawn in scale. A total of 1,020 individuals of 45 families and 115 species was sampled. The fragments varies in number of individuals (300-399 individuals), families ( $\mathrm{N}=26-32)$ and species $(\mathrm{N}=54-68)$, height and successional stages, indicating high heterogeneity within a continuous forest, from the mature successional stages to the first ones. These discoveries have implications for conservation management and the ecosystem service they provide.
\end{abstract}

Keywords: Atlantic Rainforest, Phytosociology, Sucession

RESUMO - (Florestas secundárias do Parque Estadual da Cantareira, São Paulo, SP, Brasil: Variações florísticas e estruturais). O Parque Estadual da Cantareira, no bioma da Mata Atlântica, foi criado a partir da desapropriação de fazendas de café para proteção de mananciais para a cidade de São Paulo em 1877. Desde então, poucas atividades humanas ocorreram em seu interior. Aqui, comparamos a composição e o estágio sucessional de diferentes fragmentos de floresta próximos $(<0,5 \mathrm{~km}$ um do outro). Foram levantados 0,6 ha, divididos em três áreas de 0,2 ha cada, com árvores atingindo PAP $\geq 15 \mathrm{~cm}$, sendo amostradas, identificadas e medidos o diâmetro e a altura. O estágio sucessional das espécies foi determinado e um perfil de cada área foi desenhado em escala. Um total de 1.020 indivíduos pertencentes a 45 famílias e 115 espécies foi amostrado. Os fragmentos variaram em número de indivíduos (300-399 indivíduos), famílias ( $\mathrm{N}=26-32)$ e espécies $(\mathrm{N}=54-68)$, altura e estágios sucessionais, indicando alta heterogeneidade dentro de uma floresta contínua, desde os estágios sucessionais maduros até os iniciais. Essas descobertas têm implicações para o manejo da conservação e os serviços ecossistêmicos fornecidos por eles. Palavras-chave: Fitossociologia, Mata Atlântica, Sucessão

\section{Introdução}

A Mata Atlântica ocupa aproximadamente $15 \%$ do território brasileiro sendo considerada mundialmente o $5^{\circ}$ bioma mais ameaçado (Fundação SOS Mata Atlântica 2020). Estende-se desde o Piauí até o Estado do Rio Grande do Sul, englobando assim 17 Estados brasileiros (São Paulo 2010, Fundação SOS Mata Atlântica 2020). A ampla variação de temperatura, relevo e solo ao longo da Mata Atlântica, fazem desta uma das florestas de maior biodiversidade do mundo (Leitão-Filho 1987, Lino \& Amaral 2018). Pelo alto número de espécies endêmicas e forte pressão antrópica, o Bioma Mata Atlântica, juntamente com o Cerrado, é considerado um dos hostspots do planeta (Myers et al. 2000)

A Mata Atlântica é composta pelas seguintes formações vegetais: Floresta Ombrófila Densa, Aberta e Mista (conhecida como Floresta de Araucárias); Floresta Estacional Semidecidual e Decidual; Campos de Altitude; Manguezais, Restingas, Campos Sulinos e Áreas Aluviais;
Áreas de Tensão Ecológica; Refúgios Vegetacionais (IBGE 2019, Fundação SOS Mata Atlântica 2020).

As Florestas Ombrófilas Densas se subdividem em 5 grupos principais: Floresta Ombrófila Densa de Terras Baixas, presente até 50 metros de altitude; Floresta Ombrófila Densa Submontana, 50 a 500 metros; Floresta Ombrófila Densa Montana, 500 a 1500 metros e a Floresta Ombrófila Densa Altomontana, acima de 1500 metros, e a Floresta Ombrófila Densa Aluvial, presente em qualquer das formações anteriores, ao longo dos cursos d'água (IBGE 2012).

No Estado de São Paulo, a diminuição drástica da cobertura florestal deveu-se a fatores antrópicos, principalmente o estabelecimento de culturas, inicialmente a do café e o adensamento populacional nos núcleos urbanos (Rocha \& Costa 1998, RBMA 2019).

Apesar da destruição da floresta ao longo da história de São Paulo, o Estado ainda preserva a maior área contínua da Mata Atlântica no Brasil, nas encostas da Serra do Mar (Leite 2007).

1. Parte da Dissertação de Mestrado do primeiro Autor

2. Instituto de Botânica, Avenida Miguel Estefano, 3.687, 04301-902 São Paulo, SP, Brasil

3. Instituto Florestal, Rua do Horto, 931, 02377-000 São Paulo, SP, Brasil

4. Autora para correspondência: rafaela_valeck@hotmail.com 
Alguns trabalhos mais recentes relatam o aumento da cobertura florestal, representada por florestas secundárias em diferentes estágios de regeneração (Farinaci \& Batistella 2012). O que resta da Mata Atlântica está inserido em 1.324 Unidades de Conservação (UCs).

A sucessão é o processo natural de desenvolvimento da comunidade vegetal que possibilita o estabelecimento de plantas em uma área desprovida de vegetação ou a regeneração da vegetação onde esta sofreu algum tipo de distúrbio (Brancalion et al. 2015).

Para cada fase da sucessão em uma floresta secundária, há predomínio de determinadas espécies pertencentes a um grupo sucessional (Clements 1916). Segundo Whitmore (1989), o conhecimento sobre a substituição de espécies ao longo do processo de sucessão é fundamental para avaliar o grau de maturidade em que se encontra um determinado fragmento florestal.

Conforme a tabela 1 , o primeiro estudo a classificar as espécies por suas respectivas categorias foi realizado por Budowski (1965), este utilizou as categorias pioneira, secundária inicial, secundária tardia e clímax. Posteriormente, alguns autores classificaram as espécies de forma mais sucinta, ou seja, espécies pioneiras e nãopioneiras como: Gómez-Pompa (1971), Whitmore (1989) e Lima et al. (2011). Já, em outros estudos, os autores optaram por classificar as espécies separando as não pioneiras, por secundárias iniciais e secundárias tardias e as espécies típicas de sub-bosque ou conhecidas como umbrófilas.

Portanto, conforme as análises dos estudos apresentados na tabela 1 , as espécies pioneiras predominam no início da sucessão, podem ser encontradas em grandes clareiras, produzem sementes pequenas e abundantes, que necessitam de luz direta para germinar, além disso tem crescimento rápido e ciclo de vida curto; as espécies secundárias iniciais estabelecem-se em pequenas clareiras, assemelham-se às pioneiras quanto à necessidade de luz para germinar suas sementes, mas têm ciclo de vida mais longo; as secundárias tardias destacam-se na fase mais madura da floresta, suas sementes não necessitam de luz direta para germinar e são geralmente maiores, menos abundantes que as das espécies pioneiras, podem apresentar dormência e suas plântulas vivem na sombra, com crescimento lento e ciclo de vida longo; as espécies umbrófilas ou típicas de sub-bosque, estão presentes em todas as fases, mas com maior densidade na fase madura. O que as diferencia das secundárias tardias é seu ciclo de vida inteiramente no interior da floresta (Budowski 1965, Gómez-Pompa 1971, Swaine \& Whitmore 1988, Kageyama \& Castro 1989, Gandolfi 1991, Catharino et al. 2006).

No Estado de São Paulo, uma importante unidade de conservação é o Parque Estadual da Cantareira, localizado na região metropolitana da cidade de São Paulo, sendo um dos principais remanescentes florestais, formados por florestas secundárias em diferentes estágios sucessionais, porém mantendo alta riqueza de biodiversidade.

Estudos sobre a dinâmica do processo sucessional em florestas do Planalto Paulista são escassos. Portanto, o presente estudo poderá fornecer contribuições para a temática e para aplicações práticas no âmbito local e regional.

O objetivo deste estudo foi comparar quanto ao estágio sucessional, trechos da floresta do Parque Estadual da Cantareira através da análise de sua estrutura e espécies características de seus estratos, contribuindo para o conhecimento, conservação e a proteção das florestas secundárias urbanas.

Para tanto elaboramos as seguintes perguntas:

A. Como a composição florística e a estrutura variam nas áreas analisadas?

B. É possível reconhecer estágios sucessionais diferentes nas áreas estudadas?

C. Como as espécies de diferentes grupos sucessionais estão representadas nas áreas estudadas?

Tabela 1. Classificação sucessional das espécies.

Table 1. Successional classification of species.

\begin{tabular}{|c|c|c|}
\hline Ano & Autor & Classificação \\
\hline 1965 & Budowski & Pioneira, secundária inicial, secundária tardia e clímax \\
\hline 1971 & Gómez-Pompa & Primária e secundária \\
\hline 1980 & Denslow & Pioneira, secundária e sub-bosque \\
\hline 1989 & Whitmore & Pioneira e Clímax \\
\hline 1989 & Kageyama \& Castro & Pioneira, clímax e sub-bosque \\
\hline 1991 & Gandolfi & Pioneira, secundária inicial e secundária tardia \\
\hline 1992 & Rodrigues \& Shepherd & Pioneira, secundária inicial, secundária tardia e típica de sub-bosque \\
\hline 1994 & Tabarelli & Pioneira, secundária inicial, secundária tardia e clímax \\
\hline 1996 & Bernacci \& Leitão-Filho & Pioneira, secundária inicial e secundária tardia \\
\hline 1997 & Aragaki & Pioneira, secundária inicial e secundária tardia \\
\hline 2001 & Aguiar et al. & Pioneira, secundária inicial, secundária tardia e clímax \\
\hline 2006 & Catharino et al. & Pioneira, secundária inicial, secundária tardia e umbrófila \\
\hline 2007 & Polisel \& Franco & Pioneira, secundária, tardia e umbrófila \\
\hline 2011 & Lima et al. & Pioneira e não-pioneira \\
\hline 2011 & Arzolla & Pioneira, secundária inicial, secundária tardia e umbrófila \\
\hline 2013 & Barretto & Pioneira, secundária inicial e secundária tardia \\
\hline 2017 & Moura \& Mantovani & Pioneira, secundária inicial, secundária tardia e sub-bosque \\
\hline
\end{tabular}




\section{Material e Métodos}

Área de Estudo - O Parque Estadual da Cantareira (PEC) possui 7.916,5 hectares, abrangendo parte dos munícipios de Caieiras, Guarulhos, Mairiporã e São Paulo, na bacia do Alto Tietê, na Serra da Cantareira. Destaca-se entre seus serviços ecossistêmicos a sua grande riqueza de mananciais (São Paulo, 2010).

Essa região era anteriormente composta por fazendas de café, que foram adquiridas pelo governo do Estado, para garantir o abastecimento de água para a cidade de São Paulo. A captação de água na Serra da Cantareira iniciouse em 1877. O abastecimento acontecia a partir de um sistema de pequenas represas, suficientes para abastecer a população que residia no centro da cidade com uma água de excelente qualidade. Com o aumento da urbanização, os mananciais da Serra da Cantareira deixaram de ser suficientes para o abastecimento da cidade de São Paulo. Atualmente, apenas uma parte do município de Guarulhos é abastecida pelos mananciais do PEC (São Paulo, 2010).

Como resultado deste histórico, formou-se uma floresta secundária, onde predominam manchas em fases intermediárias de sucessão (Baitello et al. 1993, Arzolla 2002, São Paulo 2010).
O PEC é composto por 4 zonas administrativas: Núcleo Engordador, localizado entre os municípios de Mairiporã e São Paulo; Águas Claras, no município de Mairiporã; Cabuçu em Guarulhos e Pedra Grande, que abrange parte dos municípios de Caieiras, Mairiporã e São Paulo (Ayres 2006, São Paulo 2010).

A área de estudo está localizada no Núcleo Pedra Grande. Conforme o IBGE (2012), a área é recoberta pela Floresta Ombrófila Densa Montana. De acordo com a classificação de Köppen, o clima é do tipo úmido, temperado e sem estação seca - Cfb (São Paulo 2010), ou seja, com precipitação média do mês mais seco $>30 \mathrm{~mm}$ e a temperatura média do mês mais quente $<22^{\circ} \mathrm{C}$ (Köppen 2019). O relevo é montanhoso, com amplitudes de 120 a 400 metros e altitudes de 875 a 1215 metros (São Paulo, 2010).

Métodos - Para o presente estudo foram selecionadas três áreas amostrais de 0,2 ha cada, subdivididas em dez parcelas contíguas de $10 \times 20 \mathrm{~m}$, totalizando uma área amostral de 0,6 ha. A distância aproximada entre a área $\mathrm{C}$ e $\mathrm{A}$ é de $250 \mathrm{~m}$ e da área A para B de $400 \mathrm{~m}$, com as respectivas localizações:

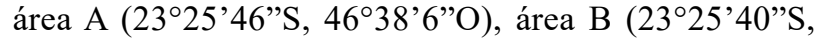

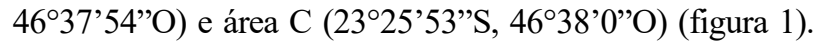
As três áreas encontram-se afastadas das trilhas para se evitar o efeito de borda, como recomendado por Rodrigues $\&$ Shepherd (1992) e possuem declividades semelhantes.

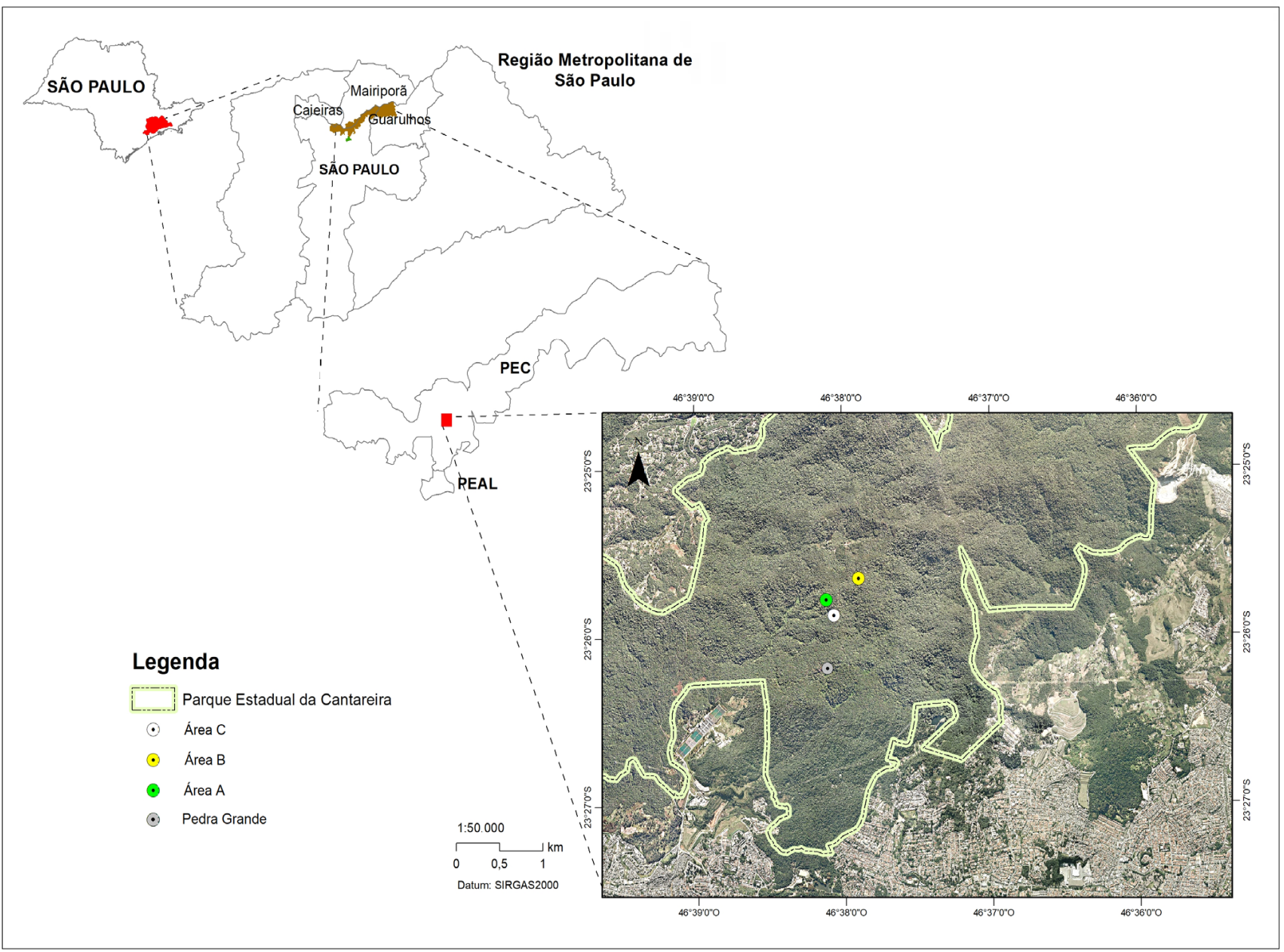

Figura 1. Mapa com a localização das três áreas de estudo, Parque Estadual da Cantareira, São Paulo, SP, Brasil. Elaborado por Marina Kanashiro, 2019.

Figure 1. Map with the location of the three study areas, Parque Estadual da Cantareira, São Paulo, São Paulo State, Brasil. Prepared by Marina Kanashiro, 2019. 
Foram amostrados todos os indivíduos com PAP, perímetro do tronco à altura de $1,30 \mathrm{~m}$ acima do solo $\geq 15 \mathrm{~cm}$. Os indivíduos mortos, mesmo em pé, não foram amostrados. A altura das árvores foi estimada utilizando-se tesoura de poda alta como referência. As amostras botânicas foram coletadas, herborizadas e identificadas por comparação com exsicatas depositadas em herbário, consultas a especialistas e bibliografias específicas. As amostras férteis foram registradas e incorporadas no Herbário Dom Bento Pickel (SPSF) do Instituto Florestal.

Para a classificação das famílias, foi utilizado o Angiosperm Phylogeny Group - APG IV (APG - Angiosperm Phylogeny Group 2016). Os nomes científicos foram conferidos com a lista de espécies da Flora do Brasil (Flora do Brasil 2020 - em construção 2020).

Os parâmetros fitossociológicos calculados nas análises foram: número de indivíduos (ni), densidade relativa (DR), dominância relativa (DoR), frequência relativa (FR), valor de cobertura (VC) e valor de importância (VI), segundo Mueller-Dombois \& Ellenberg (1974). Também foram realizadas análises multivariadas de classificação e ordenação, utilizando-se matrizes de número de indivíduos, para verificar a eventual formação de grupos nas unidades amostrais da área de estudo e comparar as parcelas e blocos entre si. Nas análises de classificação, para comparação de matrizes de números de indivíduos, foram utilizados os métodos UPGMA Unweighted Pair Group Method with Arithmetic Mean com coeficiente de Bray-Curtis. Como método de ordenação foi utilizado CA (Análise de Correspondência). Para esses cálculos e análises, foi utilizado o programa Fitopac 2.1 (Shepherd 2010).

As espécies foram classificadas segundo o tipo de dispersão de seus propágulos, como zoocóricas, anemocóricas e autocóricas, de acordo com Arzolla (2002, 2011); Catharino et al. (2006) e Moura \& Mantovani (2017).

A apresentação das espécies ameaçadas deu-se pelas consultas às seguintes listas: IUCN (2020), nacional (Portaria MMA n ${ }^{\circ} 443$, de 17 de dezembro de 2014 - Brasil 2020) e estadual (Resolução SMA N N $^{\circ}$, de 05 de junho de 2016 - São Paulo 2016).

A classificação das espécies, segundo a categoria sucessional, foi baseada, principalmente, em observações de campo e em trabalhos realizados por Arzolla (2011) e Catharino et al. (2006). Foram feitas duas classificações sucessionais, uma com quatro categorias: pioneiras, secundárias iniciais, secundárias tardias e umbrófilas, sendo as três primeiras conforme Budowski (1965) e, as umbrófilas, segundo Catharino et al. (2006) e Arzolla (2011); a segunda considerou as espécies como pioneiras (pioneiras e secundárias iniciais) e não-pioneiras (secundárias tardias e umbrófilas), adaptado de Barbosa (2017).

Para auxiliar uma análise da distribuição das espécies em categoria sucessional, foram idealizados perfis diagramas totais de cada uma das áreas estudadas, com a representação dos indivíduos amostrados seguindo-se a sequência da planilha de campo, com núcleos diferentes segundo sua classificação sucessional.

\section{Resultados}

Composição Florística - No levantamento geral, foram amostrados 1020 indivíduos, distribuídos em 115 espécies, 80 gêneros e 45 famílias (tabela 2). A área B é mais rica, com 68 espécies, sendo $21 \%$ mais rica que C (56 spp.) e $26 \%$ mais rica que A (54 spp.).

As famílias mais ricas em espécies foram Myrtaceae (17 espécies), Lauraceae (12), Fabaceae (8), Rubiaceae e Meliaceae (5). As famílias mais abundantes em indivíduos foram Euphorbiaceae (127 indivíduos), Myrtaceae (115), Olacaceae (114), Rubiaceae (108) e Meliaceae (68).

Os gêneros mais ricos foram Eugenia, Myrcia e Ocotea (sete espécies cada), Mollinedia (quatro) e Annona e Casearia (três cada).

Riqueza e Abundância nas Áreas A, B e C - Na Área A foram amostrados 321 indivíduos, 54 espécies e 26 famílias. As famílias com maior riqueza foram Myrtaceae (10 espécies), Lauraceae (6 esp.), Euphorbiaceae e Rubiaceae (4 esp.) e Monimiaceae (3 esp.). As famílias mais abundantes foram Rubiaceae (70 indivíduos), Olacaceae (42 ind.), Myrtaceae (32 ind.), Clusiaceae (23 ind.) e Monimiaceae (20 ind.). As famílias Rubiaceae e Olacaceae destacam-se nas primeiras posições quanto à abundância, não ocorrendo o mesmo em relação a riqueza, mostrando que a alta abundância dessas famílias deve-se a Psychotria suterella em Rubiaceae e Heisteria silvianii em Olacaceae. Os gêneros mais ricos foram Myrcia (quatro espécies), Eugenia, Ocotea e Mollinedia (três cada), Annona e Cinnamomum (duas cada). Podemos observar que dentre estes, somente Cinnamomum não se destacou nos resultados gerais.

A Área B apresentou 399 indivíduos, 68 espécies e 32 famílias. As famílias com maior riqueza foram Myrtaceae (10 espécies), Lauraceae (7 esp.), Meliaceae (5 esp.), Sapindaceae e Monimiaceae (4 esp.). As famílias mais abundantes em número de indivíduos foram Myrtaceae (72 indivíduos), Sapindaceae (39 ind.), Meliaceae (38 ind.), Olacaceae (37 ind.) e Rubiaceae (31 ind.). Nesta área, Sapindaceae e Meliaceae destacaram-se tanto no levantamento por espécies quanto de indivíduos. Os gêneros que se destacaram nesta área foram Eugenia (cinco espécies), Mollinedia, Myrcia e Ocotea (quatro espécies cada), também amostradas na área $\mathrm{A}$, seguidas de Casearia (três) e Matayba (duas).

A área $C$ apresentou 300 indivíduos pertencentes a 56 espécies e 30 famílias. As famílias mais ricas foram Fabaceae (7 espécies), Lauraceae (6 esp.), Euphorbiaceae e Myrtaceae (4 esp.) e Meliaceae (2 esp.). As famílias Fabaceae e Euphorbiaceae também foram as mais ricas no levantamento realizado na Floresta Ombrófila Densa situada no município de Cunha - SP por Aguiar et al. (2001). As famílias mais abundantes foram Euphorbiaceae (94 ind.), Olacaceae (35 ind.), Fabaceae (32 ind.), Meliaceae (16 ind.) e Lauraceae (15 ind). Em relação aos gêneros, aqueles que mais se destacaram nesta análise foram Annona, Croton, Mollinedia, Myrcia, Myrsine, Nectandra, Ocotea e Vochysia (duas espécies cada). 
Tabela 2. Composição florística nas três áreas amostradas (A, B e C), Parque Estadual da Cantareira, São Paulo, SP, Brasil. Class. Sucess.: Classificação Sucessional. PI: Pioneira, I: Secundária inicial, T: Secundária tardia, UM: Umbrófilas, P: Pioneira, NP: Não pioneira. Sindromes dispersão. ZOO: Zoocórica, ANE: Anemocórica, AUT: Autocórica.

Table 2. Floristic composition of the three sampled areas (A, B and C), Parque Estadual da Cantareira, São Paulo, São Paulo State, Brasil. Class Sucess.: Succession Classification. PI: Pioneer, I: Early secondary, T: Late secondary, UM: Umbrophilous, P: Pioneer, NP: Non pioneer. Dispersion syndromes. ZOO: Zoochoric, ANE: Anemochoric, AUT: Autochoric.

\begin{tabular}{|c|c|c|c|c|c|c|c|c|}
\hline Família/Espécie & Nome Popular & Área & $\begin{array}{c}\text { Área } \\
\text { B }\end{array}$ & Área & $\begin{array}{l}\text { Class. } \\
\text { Sucess. }\end{array}$ & $\begin{array}{c}\text { Class. } \\
\text { Sucess. } \\
\text { (P-NP) } \\
\end{array}$ & $\begin{array}{l}\text { Síndrome } \\
\text { dispersão }\end{array}$ & $\begin{array}{l}N^{\circ} \text { de } \\
\text { coleta }\end{array}$ \\
\hline $\begin{array}{l}\text { Anacardiaceae } \\
\text { Schinus terebinthifolia } \text { Raddi }\end{array}$ & aroeira-pimenteira & & & $\mathrm{X}$ & PI & $\mathrm{P}$ & $\mathrm{ZOO}$ & 103 \\
\hline $\begin{array}{l}\text { Annonaceae } \\
\text { Annona dolabripetala Raddi }\end{array}$ & araticum & & & $\mathrm{X}$ & I & $P$ & $\mathrm{ZOO}$ & 117 \\
\hline Annona emarginata (Schltdl.) H.Rainer & araticum-mirim & $\mathrm{X}$ & & & I & $\mathrm{P}$ & $\mathrm{ZOO}$ & 55 \\
\hline Annona sylvatica A.St.-Hil. & araticum-do-mato & $\mathrm{X}$ & $\mathrm{X}$ & $\mathrm{X}$ & I & $P$ & $\mathrm{ZOO}$ & 59 \\
\hline $\begin{array}{l}\text { Apocynaceae } \\
\text { Aspidosperma olivaceum Müll.Arg. }\end{array}$ & guatambu & $\mathrm{X}$ & $\mathrm{X}$ & $\mathrm{X}$ & $\mathrm{T}$ & NP & ANE & 61 \\
\hline $\begin{array}{l}\text { Arecaceae } \\
\quad \text { Geonoma schottiana Mart. }\end{array}$ & guaricanga & & $\mathrm{X}$ & & UM & NP & $\mathrm{ZOO}$ & 74 \\
\hline Syagrus romanzoffiana (Cham.) Glassman & jerivá & & $\mathrm{X}$ & & I & $\mathrm{P}$ & $\mathrm{ZOO}$ & 88 \\
\hline $\begin{array}{l}\text { Asteraceae } \\
\quad \text { Piptocarpha macropoda (DC.) Baker }\end{array}$ & vassourão & & & $\mathrm{X}$ & PI & $\mathrm{P}$ & ANE & 97 \\
\hline $\begin{array}{l}\text { Bignoniaceae } \\
\text { Jacaranda macrantha Cham. }\end{array}$ & carobinha & & & $\mathrm{X}$ & I & $\mathrm{P}$ & ANE & 118 \\
\hline $\begin{array}{l}\text { Boraginaceae } \\
\quad \text { Cordia sellowiana Cham. }\end{array}$ & louro-mole & $\mathrm{X}$ & $\mathrm{X}$ & $X$ & I & $\mathrm{P}$ & $\mathrm{ZOO}$ & 47 \\
\hline $\begin{array}{l}\text { Burseraceae } \\
\text { Protium heptaphyllum (Aubl.) Marchand }\end{array}$ & almecegueira & & $X$ & & I & $\mathrm{P}$ & $\mathrm{ZOO}$ & 130 \\
\hline $\begin{array}{l}\text { Cardiopteridaceae } \\
\text { Citronella paniculata (Mart.) R.A.Howard }\end{array}$ & congonha & & $\mathrm{X}$ & & $\mathrm{T}$ & NP & $\mathrm{ZOO}$ & 127 \\
\hline $\begin{array}{l}\text { Caricaceae } \\
\text { Jacaratia heptaphylla (Vell.) A.DC. }\end{array}$ & jaracatiá & & & $\mathrm{X}$ & I & $P$ & $\mathrm{ZOO}$ & 106 \\
\hline $\begin{array}{l}\text { Chrysobalanaceae } \\
\text { Hirtella hebeclada Moric. ex DC. }\end{array}$ & vermelhão & $\mathrm{X}$ & $\mathrm{X}$ & & $\mathrm{T}$ & NP & $\mathrm{ZOO}$ & 58 \\
\hline $\begin{array}{l}\text { Clusiaceae } \\
\text { Tovomitopsis paniculata (Spreng.) Planch. \& Triana }\end{array}$ & azedinho & $\mathrm{X}$ & $\mathrm{X}$ & $\mathrm{X}$ & $\mathrm{T}$ & NP & $\mathrm{ZOO}$ & 63 \\
\hline $\begin{array}{l}\text { Cyatheaceae } \\
\text { Alsophila setosa Kaulf. }\end{array}$ & samambaiaçu & $\mathrm{X}$ & & & I & $\mathrm{P}$ & ANE & 57 \\
\hline Cyathea delgadii Sternb. & samambaiaçu & $\mathrm{X}$ & & & I & $P$ & ANE & 123 \\
\hline $\begin{array}{l}\text { Elaeocarpaceae } \\
\quad \text { Sloanea guianensis (Aubl.) Benth. }\end{array}$ & sapopemba & $\mathrm{X}$ & $X$ & & $\mathrm{~T}$ & NP & $\mathrm{ZOO}$ & 129 \\
\hline Sloanea hirsuta (Schott) Planch. ex Benth. & ouriço-do-mato & $X$ & & $\mathrm{X}$ & $\mathrm{T}$ & NP & $\mathrm{ZOO}$ & 18 \\
\hline $\begin{array}{l}\text { Euphorbiaceae } \\
\text { Alchornea triplinervia (Spreng.) Müll.Arg. }\end{array}$ & tapiá-mirim & $\mathrm{X}$ & $\mathrm{X}$ & $\mathrm{X}$ & I & $\mathrm{P}$ & $\mathrm{ZOO}$ & 13 \\
\hline Croton floribundus Spreng. & capixingui & $\mathrm{X}$ & & $\mathrm{X}$ & PI & $\mathrm{P}$ & AUT & 93 \\
\hline Croton macrobothrys Baill. & sangra d'água & $\mathrm{X}$ & $\mathrm{X}$ & $\mathrm{X}$ & PI & $\mathrm{P}$ & AUT & 60 \\
\hline Sapium glandulosum (L.) Morong & leiteiro & & $\mathrm{X}$ & $\mathrm{X}$ & PI & $\mathrm{P}$ & $\mathrm{ZOO}$ & 124 \\
\hline $\begin{array}{l}\text { Fabaceae } \\
\text { Senegalia polyphylla (DC.) Britton \& Rose }\end{array}$ & monjoleiro & & & $\mathrm{X}$ & PI & $P$ & AUT & 108 \\
\hline Bauhinia forficata Link & pata-de-vaca & & & $\mathrm{X}$ & PI & $\mathrm{P}$ & AUT & 95 \\
\hline Copaifera trapezifolia Hayne & copaiba-da-serra & $\mathrm{X}$ & & & $\mathrm{T}$ & NP & $\mathrm{ZOO}$ & 121 \\
\hline Dahlstedtia pinnata (Benth.) Malme & & & & $\mathrm{X}$ & I & $\mathrm{P}$ & AUT & 92 \\
\hline Inga sessilis (Vell.) Mart. & ingá-ferradura & & & $\mathrm{X}$ & I & $P$ & $\mathrm{ZOO}$ & 113 \\
\hline Mimosa scabrella Benth. & bracatinga & & & $\mathrm{X}$ & PI & $\mathrm{P}$ & AUT & 05 \\
\hline Piptadenia gonoacantha (Mart.) J.F.Macbr. & pau-jacaré & & & $\mathrm{X}$ & PI & $P$ & AUT & 102 \\
\hline Platymiscium floribundum Vogel & sacambú & $\mathrm{X}$ & $\mathrm{X}$ & $\mathrm{X}$ & I & $\mathrm{P}$ & ANE & 53 \\
\hline
\end{tabular}


Tabela 2 (continuação)

\begin{tabular}{|c|c|c|c|c|c|c|c|c|}
\hline Família/Espécie & Nome Popular & Área & Área & Área & $\begin{array}{l}\text { Class. } \\
\text { Sucess. }\end{array}$ & $\begin{array}{c}\text { Class. } \\
\text { Sucess. } \\
\text { (P-NP) }\end{array}$ & $\begin{array}{l}\text { Síndrome } \\
\text { dispersão }\end{array}$ & $\begin{array}{l}\mathrm{N}^{\circ} \text { de } \\
\text { coleta }\end{array}$ \\
\hline $\begin{array}{l}\text { Lauraceae } \\
\quad \text { Cinnamomum hirsutum (Lorea-Hern.) Van der Werff }\end{array}$ & & $\mathrm{X}$ & & & $\mathrm{T}$ & NP & $\mathrm{ZOO}$ & 125 \\
\hline Cinnamomum pseudoglaziovii (Lorea-Hern.) Van der Werff & canela-garuva & $\mathrm{X}$ & $\mathrm{X}$ & $\mathrm{X}$ & $\mathrm{T}$ & NP & $\mathrm{ZOO}$ & 23 \\
\hline Cryptocarya mandioccana Meisn. & & $\mathrm{X}$ & & & $\mathrm{T}$ & NP & ZOO & 56 \\
\hline Endlicheria paniculata (Spreng.) J.F.Macbr. & canela-cheirosa & & & $\mathrm{X}$ & $\mathrm{T}$ & NP & ZOO & 04 \\
\hline Nectandra membranacea (Sw.) Griseb. & & & & $\mathrm{X}$ & $\mathrm{T}$ & NP & ZOO & 107 \\
\hline Nectandra oppositifolia Nees & canela-ferrugem & & $\mathrm{X}$ & $\mathrm{X}$ & I & $\mathrm{P}$ & $\mathrm{ZOO}$ & 33 \\
\hline Ocotea glaziovii Mez & & & $\mathrm{X}$ & & $\mathrm{T}$ & NP & ZOO & 132 \\
\hline Ocotea catharinensis $\mathrm{Mez}$ & canela-preta & $\mathrm{X}$ & $\mathrm{X}$ & $\mathrm{X}$ & $\mathrm{T}$ & NP & $\mathrm{ZOO}$ & 52 \\
\hline Ocotea koscinskii Baitello \& Brotto & & & $\mathrm{X}$ & & $\mathrm{T}$ & NP & $\mathrm{ZOO}$ & 70 \\
\hline Ocotea aff. montana (Meisn.) Mez & & & $\mathrm{X}$ & & $\mathrm{T}$ & NP & $\mathrm{ZOO}$ & \\
\hline Ocotea puberula (Rich.) Nees & canela-mole & & & $\mathrm{X}$ & PI & $\mathrm{P}$ & $\mathrm{ZOO}$ & 105 \\
\hline Ocotea silvestris Váttimo-Gil & canela-branca & $\mathrm{X}$ & $\mathrm{X}$ & & $\mathrm{T}$ & NP & $\mathrm{ZOO}$ & 86 \\
\hline $\begin{array}{l}\text { Lecythidaceae } \\
\quad \text { Cariniana estrellensis (Raddi) Kuntze }\end{array}$ & jequitibá-branco & $\mathrm{X}$ & $\mathrm{X}$ & $\mathrm{X}$ & $\mathrm{T}$ & NP & ANE & 82 \\
\hline $\begin{array}{l}\text { Melastomataceae } \\
\text { Miconia budlejoides Triana. }\end{array}$ & pixiririca & & & $\mathrm{X}$ & PI & $\mathrm{P}$ & $\mathrm{ZOO}$ & 116 \\
\hline Miconia cinnamomifolia (DC.) Naudin & jacatirão & & $\mathrm{X}$ & & PI & $\mathrm{P}$ & $\mathrm{ZOO}$ & 11 \\
\hline Mouriri chamissoana Cogn. & & $\mathrm{X}$ & $\mathrm{X}$ & & $\mathrm{T}$ & NP & $\mathrm{ZOO}$ & 31 \\
\hline Pleroma granulosum (Desr.) D. Don & quaresmeira & & & $\mathrm{X}$ & PI & $\mathrm{P}$ & ANE & 101 \\
\hline $\begin{array}{l}\text { Meliaceae } \\
\quad \text { Cabralea canjerana (Vell.) Mart. }\end{array}$ & canjerana & $\mathrm{X}$ & $\mathrm{X}$ & $\mathrm{X}$ & I & $\mathrm{P}$ & $\mathrm{ZOO}$ & 32 \\
\hline Cedrela fissilis Vell. & cedro rosa & & $\mathrm{X}$ & & I & $\mathrm{P}$ & ANE & 89 \\
\hline Guarea macrophylla Vahl ssp. tuberculata (Vell.) T.D.Penn. & marinheiro & $\mathrm{X}$ & $\mathrm{X}$ & $\mathrm{X}$ & UM & NP & $\mathrm{ZOO}$ & 24 \\
\hline Trichilia pallens C.DC. & catiguá & & $\mathrm{X}$ & & UM & NP & $\mathrm{ZOO}$ & 79 \\
\hline Trichilia silvatica C.DC. & catiguá & $\mathrm{X}$ & $\mathrm{X}$ & & UM & NP & $\mathrm{ZOO}$ & 16 \\
\hline $\begin{array}{l}\text { Monimiaceae } \\
\text { Mollinedia elegans Tul. }\end{array}$ & & $\mathrm{X}$ & $\mathrm{X}$ & & $\mathrm{UM}$ & NP & $\mathrm{ZOO}$ & 48 \\
\hline Mollinedia schottiana (Spreng.) Perkins & & $\mathrm{X}$ & $\mathrm{X}$ & $\mathrm{X}$ & UM & NP & $\mathrm{ZOO}$ & 01 \\
\hline Mollinedia triflora (Spreng.) Tul. & & & $\mathrm{X}$ & & UM & NP & $\mathrm{ZOO}$ & 131 \\
\hline Mollinedia uleana Perkins & capixim & $\mathrm{X}$ & $\mathrm{X}$ & $\mathrm{X}$ & UM & NP & $\mathrm{ZOO}$ & 64 \\
\hline $\begin{array}{l}\text { Moraceae } \\
\quad \text { Ficus luschnathiana (Miq.) Miq. }\end{array}$ & figueira-branca & & & $\mathrm{X}$ & $\mathrm{UM}$ & NP & $\mathrm{ZOO}$ & 03 \\
\hline Sorocea bonplandii (Baill.) W.C.Burger et al. & canxim & $\mathrm{X}$ & $\mathrm{X}$ & $\mathrm{X}$ & $\mathrm{UM}$ & NP & $\mathrm{ZOO}$ & 51 \\
\hline $\begin{array}{l}\text { Myristicaceae } \\
\quad \text { Virola bicuhyba (Schott ex Spreng.) Warb. }\end{array}$ & bicuíba & & $\mathrm{X}$ & & $\mathrm{T}$ & NP & $\mathrm{ZOO}$ & 12 \\
\hline $\begin{array}{l}\text { Myrtaceae } \\
\text { Eugenia beaurepaireana (Kiaersk.) D.Legrand }\end{array}$ & & & $\mathrm{X}$ & & $\mathrm{T}$ & NP & $\mathrm{ZOO}$ & 90 \\
\hline Eugenia cerasiflora Miq. & guamirim & $\mathrm{X}$ & $\mathrm{X}$ & & $\mathrm{T}$ & NP & $\mathrm{ZOO}$ & 38 \\
\hline Eugenia cereja D.Legrand & & $\mathrm{X}$ & & & $\mathrm{T}$ & NP & $\mathrm{ZOO}$ & 62 \\
\hline Eugenia involucrata DC. & cereja-do-rio-grande & $\mathrm{X}$ & & & $\mathrm{T}$ & NP & $\mathrm{ZOO}$ & 68 \\
\hline Eugenia prasina O.Berg & & & $\mathrm{X}$ & & $\mathrm{T}$ & NP & ZOO & 20 \\
\hline Eugenia subterminalis DC. & & & $\mathrm{X}$ & & $\mathrm{T}$ & NP & $\mathrm{ZOO}$ & 19 \\
\hline Eugenia supraaxillaris Spring & & $\mathrm{X}$ & $\mathrm{X}$ & $\mathrm{X}$ & $\mathrm{T}$ & NP & $\mathrm{ZOO}$ & 77 \\
\hline Marlierea racemosa (Vell.) Kiaersk. & & $\mathrm{X}$ & & & $\mathrm{T}$ & NP & $\mathrm{ZOO}$ & 65 \\
\hline Myrcia anacardiifolia Gardner & marmelinho & $\mathrm{X}$ & & & $\mathrm{T}$ & NP & $\mathrm{ZOO}$ & 45 \\
\hline Myrcia hebepetala DC. & guamirim & $\mathrm{X}$ & & & $\mathrm{T}$ & NP & $\mathrm{ZOO}$ & 119 \\
\hline Myrcia neobrasiliensis A.R.Lourenço \& E.Lucas & araçarana & $\mathrm{X}$ & $\mathrm{X}$ & $\mathrm{X}$ & $\mathrm{T}$ & NP & $\mathrm{ZOO}$ & 49 \\
\hline Myrcia neolucida A.R.Lourenço \& E.Lucas & araçarana & $\mathrm{X}$ & & & $\mathrm{T}$ & NP & $\mathrm{ZOO}$ & 28 \\
\hline Myrcia splendens (Sw.) DC. & guamirim & & $\mathrm{X}$ & $\mathrm{X}$ & I & $\mathrm{P}$ & $\mathrm{ZOO}$ & 54 \\
\hline Myrcia tenuivenosa Kiaersk. & cambuí & & $\mathrm{X}$ & & $\mathrm{T}$ & NP & $\mathrm{ZOO}$ & 91 \\
\hline Myrcia tijucensis Kiaersk. & guamirim-ferro & $\mathrm{X}$ & $\mathrm{X}$ & $\mathrm{X}$ & $\mathrm{T}$ & NP & $\mathrm{ZOO}$ & 84 \\
\hline Myrcia tomentosa (Aubl.) DC. & goiaba-brava & & $\mathrm{X}$ & & $\mathrm{T}$ & NP & $\mathrm{ZOO}$ & 39 \\
\hline Myrcia sp. & & $\mathrm{X}$ & & & $\mathrm{T}$ & NP & ZOO & 54 \\
\hline $\begin{array}{l}\text { Nyctaginaceae } \\
\quad \text { Guapira opposita (Vell.) Reitz }\end{array}$ & maria-mole & $X$ & $X$ & $X$ & I & $\mathrm{P}$ & $\mathrm{ZOO}$ & 08 \\
\hline
\end{tabular}




\begin{tabular}{|c|c|c|c|c|c|c|c|c|}
\hline Família/Espécie & Nome Popular & Área & $\begin{array}{c}\text { Área } \\
\text { B }\end{array}$ & Área & $\begin{array}{l}\text { Class. } \\
\text { Sucess. }\end{array}$ & $\begin{array}{c}\text { Class. } \\
\text { Sucess. } \\
\text { (P-NP) }\end{array}$ & $\begin{array}{l}\text { Síndrome } \\
\text { dispersão }\end{array}$ & $\begin{array}{l}\mathrm{N}^{\mathrm{o}} \text { de } \\
\text { coleta }\end{array}$ \\
\hline $\begin{array}{l}\text { Olacaceae } \\
\quad \text { Heisteria silvianii Schwacke }\end{array}$ & brinco-de-mulata & $X$ & $\mathrm{X}$ & $\mathrm{X}$ & $\mathrm{T}$ & NP & $\mathrm{ZOO}$ & 14 \\
\hline $\begin{array}{l}\text { Oleaceae } \\
\text { Chionanthus filiformis (Vell.) P.S.Green }\end{array}$ & azeitona-do-mato & $X$ & & & $\mathrm{~T}$ & NP & $\mathrm{ZOO}$ & 35 \\
\hline $\begin{array}{l}\text { Peraceae } \\
\quad \text { Pera glabrata (Schott) Baill. }\end{array}$ & cabeluda-do-mato & $X$ & & & I & $\mathrm{P}$ & $\mathrm{ZOO}$ & 120 \\
\hline $\begin{array}{l}\text { Phyllantaceae } \\
\text { Hyeronima alchorneoides Allemão }\end{array}$ & urucuruna & $\mathrm{X}$ & & $\mathrm{X}$ & I & $\mathrm{P}$ & $\mathrm{ZOO}$ & 100 \\
\hline $\begin{array}{l}\text { Phytolaccaceae } \\
\text { Seguieria langsdorffii Moq. }\end{array}$ & limoeiro-do-mato & & & $\mathrm{X}$ & I & $P$ & ANE & 112 \\
\hline $\begin{array}{l}\text { Picramniaceae } \\
\quad \text { Picramnia glazioviana Engl. }\end{array}$ & cafezinho & X & & & $\mathrm{T}$ & NP & $\mathrm{ZOO}$ & 30 \\
\hline $\begin{array}{l}\text { Polygonaceae } \\
\text { Ruprechtia laxiflora Meisn. }\end{array}$ & marmeleiro-do-mato & & $\mathrm{X}$ & & $\mathrm{T}$ & NP & ANE & 115 \\
\hline $\begin{array}{l}\text { Primulaceae } \\
\text { Myrsine gardneriana A.DC. }\end{array}$ & capororoca & & & $\mathrm{X}$ & PI & $\mathrm{P}$ & $\mathrm{ZOO}$ & 109 \\
\hline Myrsine umbellata Mart. & capororoca & & & $\mathrm{X}$ & I & $\mathrm{P}$ & $\mathrm{ZOO}$ & 110 \\
\hline $\begin{array}{l}\text { Proteaceae } \\
\quad \text { Euplassa cantareirae Sleumer }\end{array}$ & $\begin{array}{l}\text { carvalho-da- } \\
\text { cantareira }\end{array}$ & $X$ & & & $\mathrm{~T}$ & NP & $\mathrm{ZOO}$ & 50 \\
\hline $\begin{array}{l}\text { Rosaceae } \\
\quad \text { Prunus myrtifolia (L.) Urb. }\end{array}$ & pessegueiro-bravo & & $X$ & & I & $\mathrm{P}$ & $\mathrm{ZOO}$ & 17 \\
\hline $\begin{array}{l}\text { Rubiaceae } \\
\quad \text { Cordiera myrciifolia (K.Schum.) CHPerss \& Delprete }\end{array}$ & marmelinho & & $X$ & & UM & NP & $\mathrm{ZOO}$ & 87 \\
\hline Posoqueria latifolia (Rudge) Schult. & baga-de-macaco & $\mathrm{X}$ & $\mathrm{X}$ & & I & $\mathrm{P}$ & $\mathrm{ZOO}$ & 66 \\
\hline Psychotria suterella Müll.Arg. & pasto-d'anta & $\mathrm{X}$ & $\mathrm{X}$ & $\mathrm{X}$ & UM & NP & $\mathrm{ZOO}$ & 22 \\
\hline Psychotria vellosiana Benth. & erva-de-rato & $\mathrm{X}$ & & & UM & NP & $\mathrm{ZOO}$ & 46 \\
\hline Rudgea gardenioides (Cham.) Müll.Arg. & jasmim-do-mato & $\mathrm{X}$ & & & $\mathrm{UM}$ & NP & $\mathrm{ZOO}$ & 122 \\
\hline $\begin{array}{l}\text { Rutaceae } \\
\text { Esenbeckia grandiflora Mart. }\end{array}$ & pau-de-cutia & $X$ & & & $\mathrm{~T}$ & NP & AUT & 67 \\
\hline $\begin{array}{l}\text { Salicaceae } \\
\quad \text { Casearia decandra Jacq. }\end{array}$ & guaçatonga & & $\mathrm{X}$ & & I & $\mathrm{P}$ & $\mathrm{ZOO}$ & 83 \\
\hline Casearia obliqua Spreng. & guaçatonga & $\mathrm{X}$ & $\mathrm{X}$ & & I & $\mathrm{P}$ & $\mathrm{ZOO}$ & 69 \\
\hline Casearia sylvestris $\mathrm{Sw}$. & erva de lagarto & & $\mathrm{X}$ & $\mathrm{X}$ & I & $\mathrm{P}$ & $\mathrm{ZOO}$ & 94 \\
\hline $\begin{array}{l}\text { Sapindaceae } \\
\quad \text { Allophylus petiolulatus Radlk. }\end{array}$ & fruta-de-pombo & & $\mathrm{X}$ & $\mathrm{X}$ & $\mathrm{UM}$ & NP & $\mathrm{ZOO}$ & 73 \\
\hline Cupania oblongifolia Mart. & cuvantã & & $\mathrm{X}$ & $\mathrm{X}$ & I & $\mathrm{P}$ & $\mathrm{ZOO}$ & 09 \\
\hline Matayba elaeagnoides Radlk. & camboatá-branco & $\mathrm{X}$ & $\mathrm{X}$ & & I & $P$ & $\mathrm{ZOO}$ & 76 \\
\hline Matayba guianensis Aubl. & camboatá-branco & & $\mathrm{X}$ & & I & $\mathrm{P}$ & $\mathrm{ZOO}$ & 85 \\
\hline $\begin{array}{l}\text { Sapotaceae } \\
\text { Chrysophyllum inornatum Mart. }\end{array}$ & aleixo & & $X$ & & I & $\mathrm{P}$ & $\mathrm{ZOO}$ & 75 \\
\hline Ecclinusa ramiflora Mart. & guacá & & & $\mathrm{X}$ & $\mathrm{T}$ & NP & $\mathrm{ZOO}$ & 111 \\
\hline Pouteria bullata (S.Moore) Baehni & guapeva & & $\mathrm{X}$ & & $\mathrm{T}$ & NP & $\mathrm{ZOO}$ & 114 \\
\hline $\begin{array}{l}\text { Solanaceae } \\
\quad \text { Cestrum schlechtendalii G.Don. }\end{array}$ & coerana & & $\mathrm{X}$ & & $\mathrm{P}$ & $P$ & $\mathrm{ZOO}$ & 126 \\
\hline Sessea brasiliensis Toledo & peroba-d'água & & & $\mathrm{X}$ & PI & $\mathrm{P}$ & ANE & 98 \\
\hline Solanum pseudoquina A.St.-Hil. & quina-falsa & & $\mathrm{X}$ & & I & $\mathrm{P}$ & $\mathrm{ZOO}$ & 128 \\
\hline $\begin{array}{l}\text { Symplocaceae } \\
\text { Symplocos variabilis Mart. ex Miq. }\end{array}$ & & & $\mathrm{X}$ & & UM & NP & $\mathrm{ZOO}$ & 71 \\
\hline $\begin{array}{l}\text { Thymelaeaceae } \\
\text { Daphnopsis fasciculata (Meisn.) Nevling }\end{array}$ & embira-branca & & $\mathrm{X}$ & & $\mathrm{T}$ & NP & $\mathrm{ZOO}$ & 82 \\
\hline $\begin{array}{l}\text { Urticaceae } \\
\quad \text { Urera baccifera (L.) Gaudich. ex Wedd. }\end{array}$ & urtiga & & & $\mathrm{X}$ & PI & $P$ & $\mathrm{ZOO}$ & 96 \\
\hline Cecropia glaziovii Snethl. & embaúba-vermelha & & & $\mathrm{X}$ & PI & $P$ & $\mathrm{ZOO}$ & 104 \\
\hline Coussapoa microcarpa (Schott) Rizzini & mata-pau & & $\mathrm{X}$ & & I & $\mathrm{P}$ & $\mathrm{ZOO}$ & 10 \\
\hline $\begin{array}{l}\text { Vochysiaceae } \\
\text { Vochysia magnifica Warm. }\end{array}$ & guaricica & & $X$ & $\mathrm{X}$ & I & $\mathrm{P}$ & ANE & 07 \\
\hline Vochysia selloi Warm. & & & $\mathrm{X}$ & $X$ & I & $\mathrm{P}$ & ANE & 78 \\
\hline
\end{tabular}


Ao compararmos as três áreas de estudo, Olacaceae destaca-se pela abundância nas três áreas, enquanto Myrtaceae e Rubiaceae destacam-se em duas delas. A alta representatividade de Olacaceae é devida a uma única espécie, $H$. silvianii, e Rubiaceae por $P$. suterella, enquanto que Myrtaceae, pela riqueza de espécies.

Parâmetros fitossociológicos - A tabela 3 mostra os parâmetros totais e por área, a área B apresentou 39\% do número total de indivíduos amostrados, enquanto as áreas A e C, $31 \%$ e $30 \%$ respectivamente.

$\mathrm{Na}$ área A, H. silvianii (22,7\%), Aspidosperma olivaceum (18,1\%) e Euplassa cantareirae (10,4\%), espécies secundárias tardias, apresentaram os maiores valores de dominância relativa. As espécies que se destacaram pelo valor de densidade foram $P$. suterella $(19,6 \%), H$. silvianii $(13,1 \%)$ e Tovomitopsis paniculata $(7,1 \%)$.

$\mathrm{Na}$ área B, as espécies Alchornea triplinervia (22,6\%), H. silvianii (11,1\%), Cabralea canjerana (6,8\%), Casearia obliqua (6,5\%) e Platymiscium floribundum (6,4\%) destacaram-se por seus valores de dominância relativa. Dentre elas, $H$. silvianii é a única secundária tardia e também apresentou alto valor de dominância na área $\mathrm{A}$. Destacaram-se pelo valor de densidade, H. silvianii (9,3\%), Cupania oblongifolia (8,8\%), Myrcia tijucensis (7,3\%) e P. suterella $(7,0 \%)$.

$\mathrm{Na}$ área $\mathrm{C}$, destacaram-se pelo valor de dominância Piptadenia gonoacantha (26,50\%), Croton floribundus (24,8\%), A. triplinervia (10,4\%) e Bauhinia forficata $(6,8 \%)$. Destacaram-se pelo valor de densidade, $C$. floribundus (18,0\%), H. silvianii (11,67\%), A. triplinervia $(7,7 \%)$ e $P$. gonoacantha $(6,7 \%)$.

Ao comparar as três áreas amostradas, verifica-se que apresentam estrutura e composição florística distintas. Algumas espécies aparecem nas três áreas, mas em situações diferentes, por exemplo, $H$. silvianii, destacou-se tanto na área $\mathrm{A}$ e $\mathrm{B}$, por seu valor de dominância, enquanto na área $\mathrm{C}$, pela frequência, mostrando que nas duas primeiras áreas encontra-se no dossel, enquanto em $\mathrm{C}$, nos estratos inferiores da floresta.

Ao comparar a densidade das três áreas, constatamos que B (1995 ind./ha) é a mais densa, sendo 33\% maior que $\mathrm{C}$ (1500 ind./ha) e $24 \%$ maior que A (1605 ind./ha). A maior densidade da área B pode ser explicada pelo predomínio de secundárias iniciais no dossel e pela grande quantidade de secundárias tardias no sub-bosque, estas últimas, em fase de crescimento, com um grande número de indivíduos jovens com pequenos diâmetros. Ao tratar-se de dominância, o cenário muda, pois, a área $\mathrm{C}$ apresenta a menor dominância $\left(30,6 \mathrm{~m}^{2} / \mathrm{ha}\right)$, em comparação com as áreas A e B (45,4 m²/ha e 43,4 m²/ha, respectivamente), sendo $32,5 \%$ e $29,4 \%$ menor, respectivamente, enquanto os valores da área A e B são próximos.

Os valores de DeA e DoA mostram que na área $\mathrm{A}$, há vários indivíduos com grandes diâmetros, mas estes pertencem a um mesmo grupo ecológico (secundárias tardias), indicando que a área está mais avançada na sucessão. $\mathrm{Na}$ área $\mathrm{B}$, as espécies com os maiores diâmetros pertencem a mais de um grupo ecológico, principalmente as secundárias iniciais e algumas tardias, devido à maior riqueza e ao maior número de indivíduos. $\mathrm{Na}$ área $\mathrm{C}$, a situação é bem distinta, pois tanto a DeA quanto a DoA tem valores baixos, quando comparados com $\mathrm{A}$ e $\mathrm{B}$, indicando um maior número de indivíduos com diâmetros menores.

Análises por grupos ecológicos - $\mathrm{Na}$ análise total de espécies, quanto aos seus respectivos grupos ecológicos, as secundárias tardias e iniciais mantiveram-se em proporções próximas (33,9\% e 29,6\%, respectivamente), as umbrófilas com $20 \%$ e, as pioneiras, de menor riqueza de espécies, com 16,5\%. Ao realizarmos as mesmas análises com o número de indivíduos, os resultados foram similares. Na análise por espécies pioneiras e nãopioneiras, 46,1\% são pioneiras e 53,9\% não-pioneiras e, analisando pelo número de indivíduos, 39,5\% e $60,5 \%$ respectivamente.

$\mathrm{Na}$ área $\mathrm{A}$, as secundárias tardias destacaram-se com $48,1 \%$ do total de espécies, seguidas das iniciais com $25,9 \%$, umbrófilas com $22,2 \%$ e, por fim, as pioneiras com 3,7\% (figuras 2 a, b). Nas mesmas análises com o número de indivíduos, o que se diferenciou foram as espécies umbrófilas, que tiveram um aumento de 13,7\%, em função da espécie $P$. suterella. E o oposto ocorreu com as iniciais, pois houve uma diminuição de $11,3 \%$. Na análise de espécies classificadas como pioneiras ou não pioneiras, a porcentagem foi de $70,4 \%$ e $29,6 \%$, respectivamente, enquanto abundância das espécies não-pioneiras foi 84,4\% e pioneiras, $15,6 \%$, do total de indivíduos amostrados. Esses resultados mostram que as espécies pioneiras estão representadas por um pequeno número de indivíduos.

Tabela 3. Parâmetros com valores totais e por área, Parque Estadual da Cantareira, São Paulo, SP, Brasil.

Table 3. Parameters with total values and by area, Parque Estadual da Cantareira, São Paulo, São Paulo State, Brasil.

\begin{tabular}{|c|c|c|c|c|}
\hline Parâmetros & Valores Totais & Área A & Área B & Área C \\
\hline $\mathrm{N}^{\mathrm{o}}$ de indivíduos & 1020 & 321 & 399 & 300 \\
\hline $\mathrm{N}^{\mathrm{o}}$ de espécies & 115 & 54 & 68 & 56 \\
\hline $\mathrm{N}^{\mathrm{o}}$ de famílias & 45 & 26 & 32 & 30 \\
\hline Densidade (ind./ha) & 1700 & 1605 & 1995 & 1500 \\
\hline Área basal total $\left(\mathrm{m}^{2}\right)$ & 23,88 & 9,079 & 8,677 & 6,124 \\
\hline Dominância (m²/ha) & 39,801 & 45,396 & 43,385 & 30,622 \\
\hline Indice Shannon-Wiener & 3,82 & 3,27 & 3,55 & 3,42 \\
\hline Equabilidade & 0,805 & 0,797 & 0,84 & 0,82 \\
\hline
\end{tabular}


a)

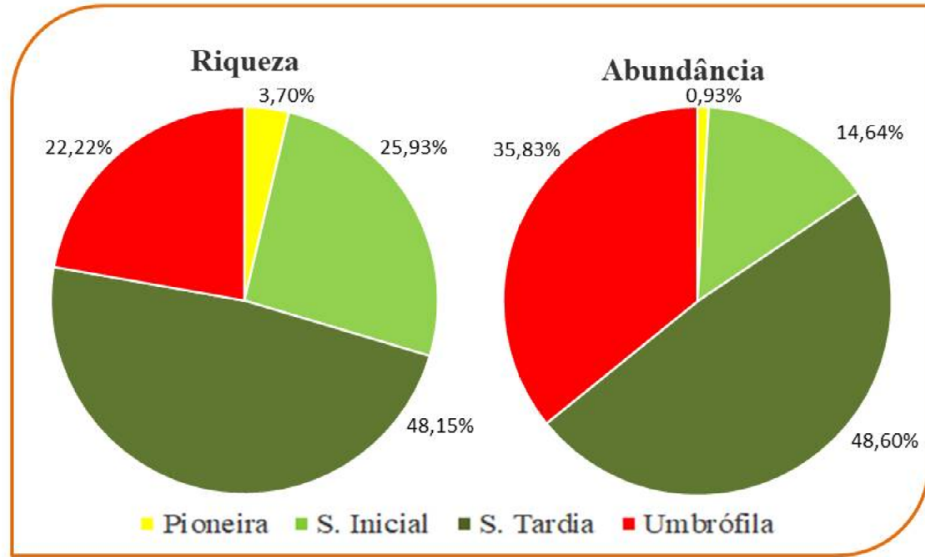

b)

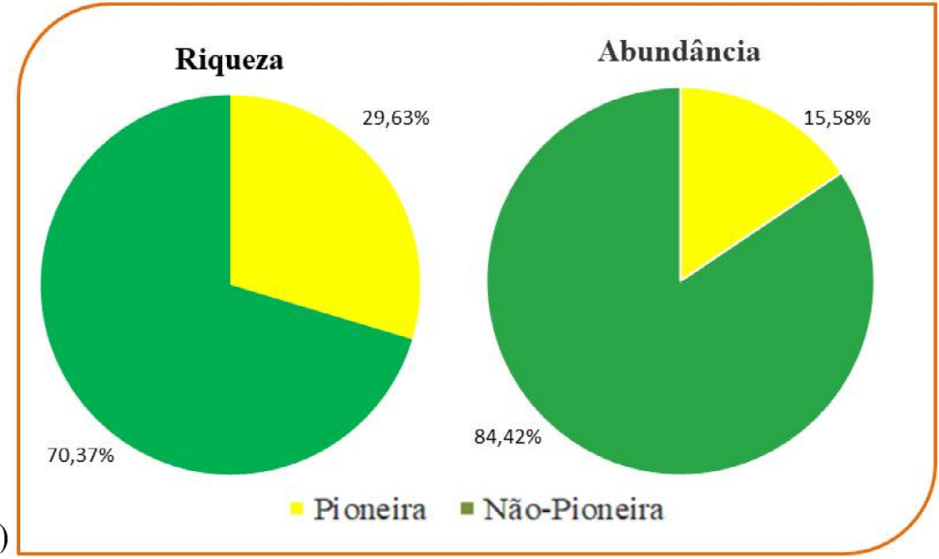

Figura 2. a. Riqueza e abundância das espécies pioneiras, secundárias iniciais, secundárias tardias e umbrófilas na área A. b. Riqueza e abundância das espécies pioneiras e não-pioneiras na área A. Parque Estadual da Cantareira, São Paulo, SP, Brasil.

Figure 2. a. Richness and abundance of pioneer, early secondary, late secondary and umbrophilous species in area A. b. Richness and abundance of pioneer or non-pioneer species in area A. Parque Estadual da Cantareira, São Paulo, São Paulo State, Brasil.

$\mathrm{Na}$ área $\mathrm{B}$, tanto as secundárias iniciais quanto as tardias compõem $35,3 \%$ do total de espécies, em seguida, as espécies umbrófilas com $22,1 \%$ e, as pioneiras, com $7,3 \%$. Nas análises realizadas com base no número de indivíduos não ocorreram grandes modificações, secundárias tardias com $37,1 \%$, iniciais, $35,1 \%$, umbrófilas, $26,6 \%$, e as pioneiras, $1,2 \%$. Na análise quanto a pioneiras e não pioneiras, a riqueza de espécies não-pioneiras foi $57,3 \%$, e pioneiras, $42,6 \%$. Quanto ao número de indivíduos, as não-pioneiras apresentaram $63,7 \%$ e as pioneiras 36,3\% (figuras $3 \mathrm{a}, \mathrm{b}$ ). Esses resultados são semelhantes quando comparamos as duas classificações sucessionais. Nesta área há maior número de pioneiras em relação à área $\mathrm{A}$.

$\mathrm{Na}$ área $\mathrm{C}$, as secundárias iniciais ainda predominam, com $32,1 \%$, seguidas das espécies pioneiras, com $28,57 \%$, as secundárias tardias, com $21,4 \%$ e, as umbrófilas, com $17,9 \%$. Nas análises de abundância, as pioneiras predominam com $40 \%$, secundárias iniciais, $29,3 \%$, tardias, $19,7 \%$, e umbrófilas, $11 \%$. Nesta área ocorre o oposto das outras duas áreas, pois as pioneiras se destacam, sendo essa diferença mais expressiva nas análises por abundância. As espécies pioneiras representam $60,7 \%$ do total de espécies e as não-pioneiras 39,3\%. Já a abundância de pioneiras e não pioneiras foi $69,3 \%$ e $30,7 \%$ respectivamente (figuras $4 \mathrm{a}$, b). De modo geral, essa área se diferencia das outras não só pelo aumento das espécies que sobrevivem em condições de luz, mas também a diminuição das espécies que vivem sobre condições de sombra, mostrando assim, que se trata de uma floresta mais aberta, em virtude do dossel descontínuo, que deixa a luz direta alcançar o solo.

$\mathrm{Na}$ área $\mathrm{A}$ as espécies secundárias tardias destacam-se pela dominância, densidade e riqueza, revelando que as espécies desse estágio estão fortemente presentes no dossel da floresta como também nos estratos inferiores.

$\mathrm{Na}$ área $\mathrm{B}$ as espécies secundárias iniciais destacam-se pela dominância, porém, nos parâmetros densidade e riqueza, as iniciais se igualam com as tardias. Esses resultados mostram que o dossel nessa área é composto, principalmente, pelas iniciais. Nos estratos inferiores os dois grupos estão fortemente presentes.

$\mathrm{Na}$ área $\mathrm{C}$ ocorre o oposto, pois, as espécies pioneiras destacam-se pela dominância, mostrando que nesse trecho as pioneiras estão presentes no dossel, porém nos parâmetros de densidade e riqueza, as pioneiras perdem o pódio, cedendo lugar para as espécies secundárias e umbrófilas.

As espécies umbrófilas aumentam da área $\mathrm{C}$ para $\mathrm{A}$, indicando que a área $\mathrm{A}$ está em fase madura de sucessão, aumentando a predominância das espécies típicas de subbosque neste estrato (figuras $5 \mathrm{a}, \mathrm{b}, \mathrm{c}$ ).

Em complemento à análise da classificação sucessional, foram elaborados perfis diagramas totais de cada uma delas, com a representação dos indivíduos amostrados, seguindo a sequência da planilha de campo. 
a)

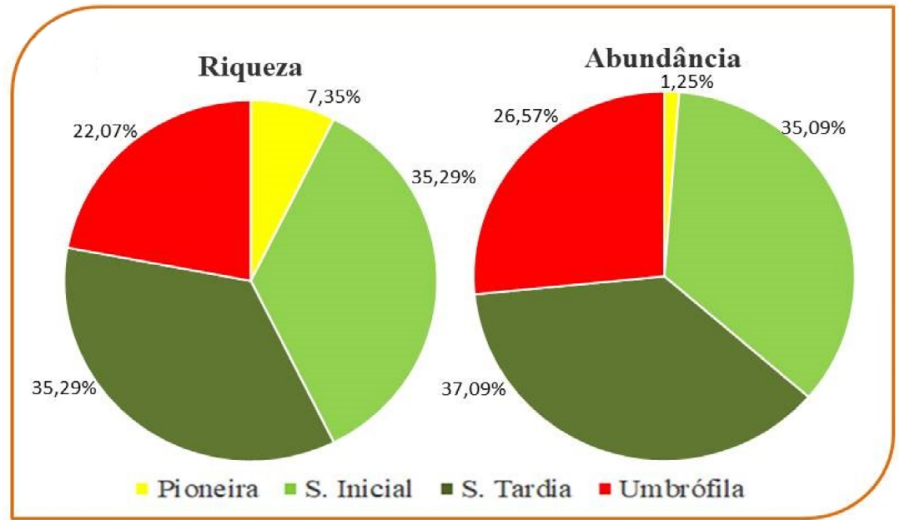

b)

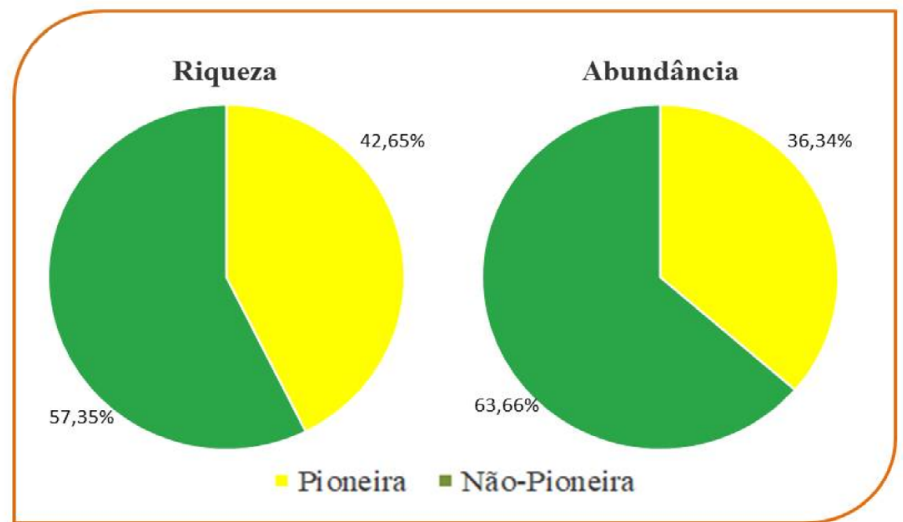

Figura 3. a. Riqueza e abundância das espécies pioneiras, secundárias iniciais e tardias e umbrófilas na área B. b. Riqueza e abundância das espécies pioneiras e não-pioneiras na área B. Parque Estadual da Cantareira, São Paulo, SP, Brasil.

Figure 3. a. Richness and abundance of pioneers, early and late secondary and umbrophilous species in area B. b. Richness and abundance of pioneer and non-pioneer species in area B. Parque Estadual da Cantareira, São Paulo, São Paulo State, Brasil.

a)

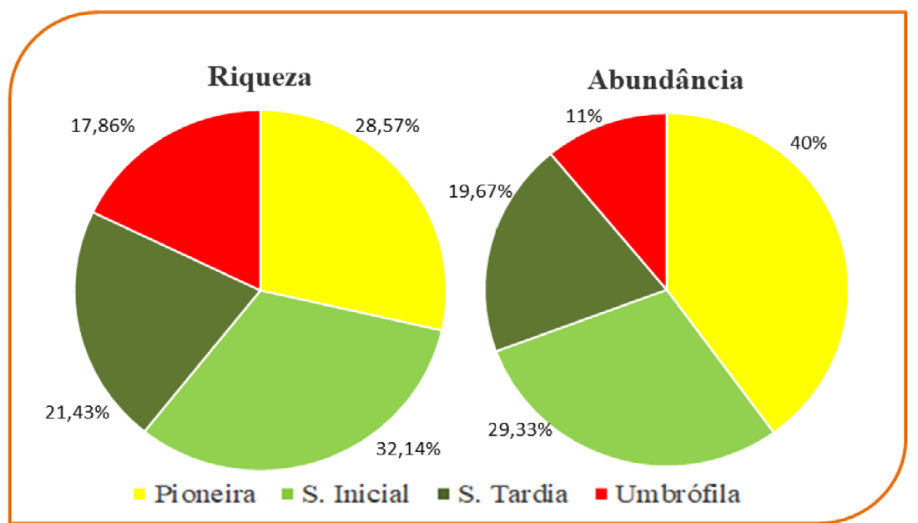

b)

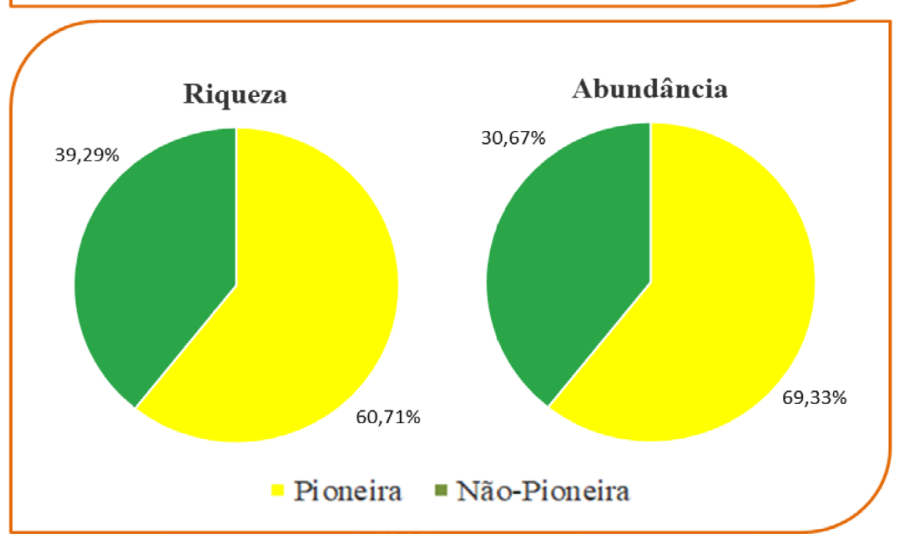

Figura 4. a. Riqueza e abundância sucessional das espécies pioneiras, secundárias iniciais e tardias e umbrófilas na área C. b. Riqueza e abundância das espécies - pioneiras e não-pioneiras na área C. Parque Estadual da Cantareira, São Paulo, SP, Brasil.

Figure 4. a. Wealth and abundance of pioneers, early and late secondary and umbrophilous in area C. b. Richness and abundance of pioneer and non-pioneer species in area C. Parque Estadual da Cantareira, São Paulo, São Paulo State, Brasil. 


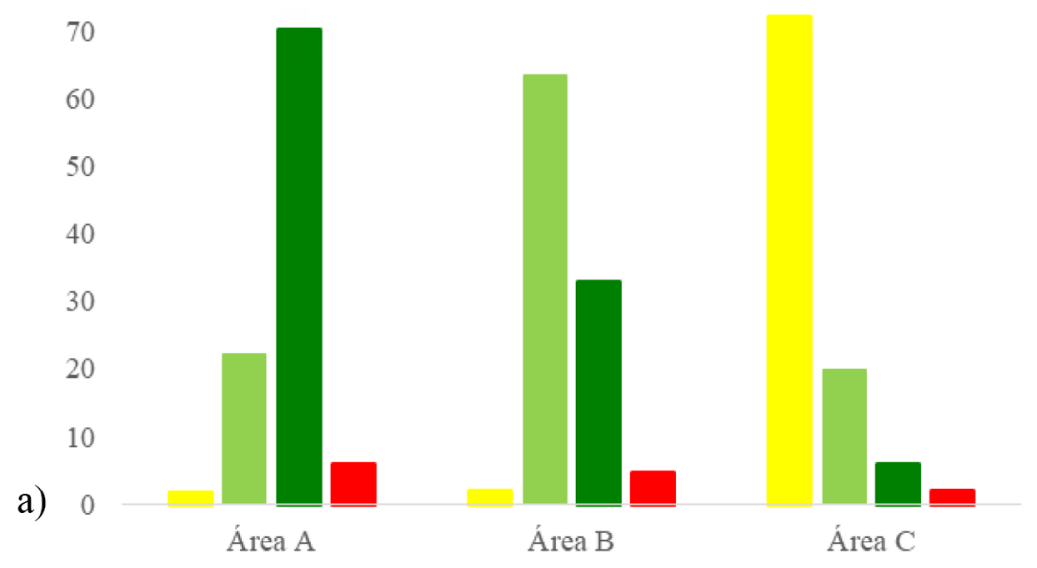

60

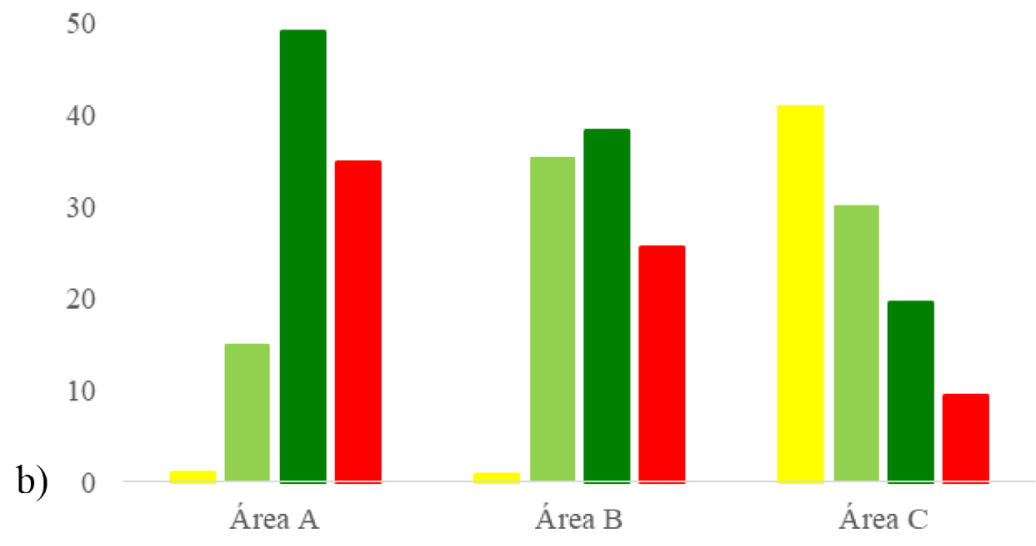

Densidade relativa

Dominância relativa

Riqueza

160
140
120
100
80
60
40
20
c)
0




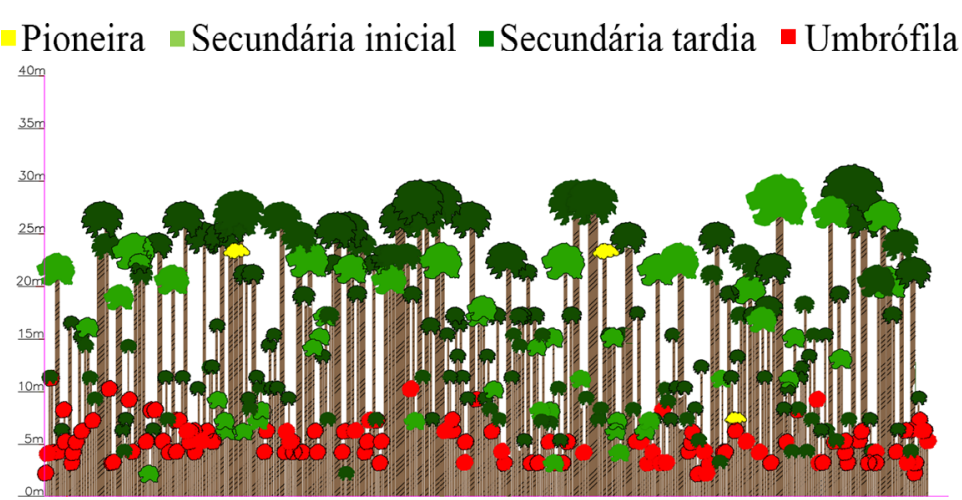

Figura 6. Diagrama de perfil da Área A, Parque Estadual da Cantareira, São Paulo, SP, Brasil.

Figure 6. Profile diagram of Area A, Parque Estadual da Cantareira, São Paulo, São Paulo State, Brasil.

\section{Pioneira $\backsim$ Secundária inicial $\backsim$ Secundária tardia - Umbrófila}

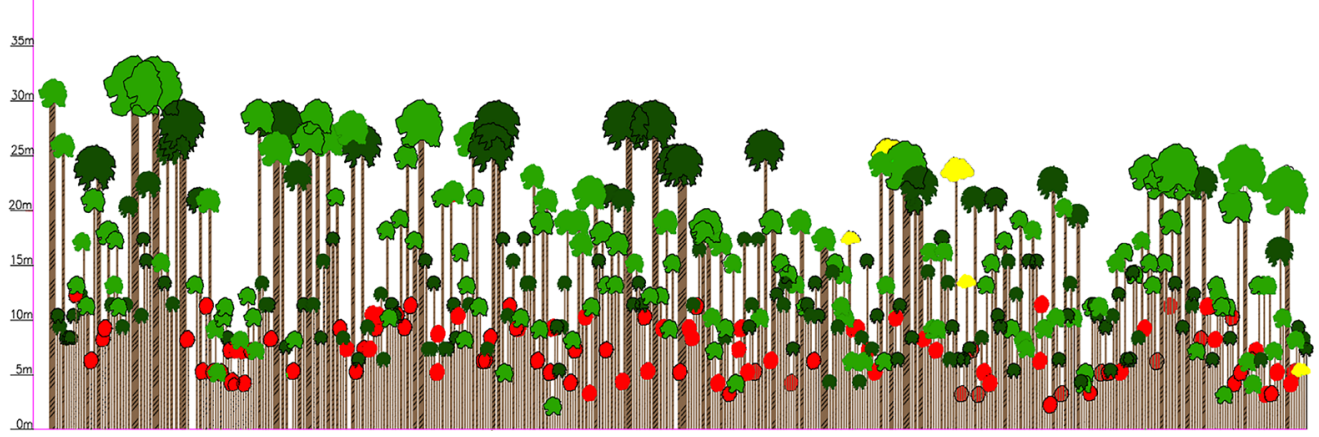

Figura 7. Diagrama de perfil da Área B, Parque Estadual da Cantareira, São Paulo, SP, Brasil.

Figure 7. Profile diagram of Area B, Parque Estadual da Cantareira, São Paulo, São Paulo State, Brasil.

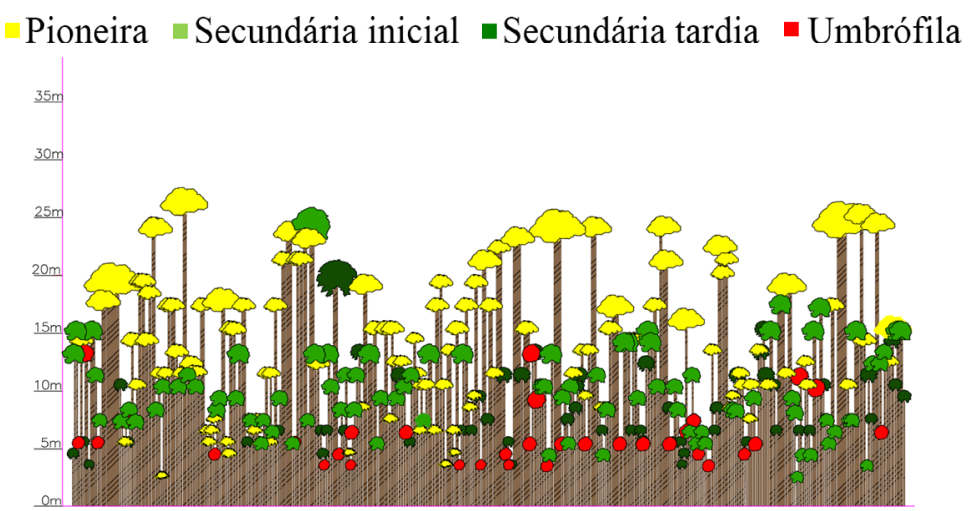

Figura 8. Diagrama de perfil da Área C, Parque Estadual da Cantareira, São Paulo, SP, Brasil.

Figure 8. Profile diagram of Area C, Parque Estadual da Cantareira, São Paulo, São Paulo State, Brasil.

De modo geral, observa-se que as três áreas são distintas, pois, na área $\mathrm{A}$, as espécies estão distribuídas conforme o esperado para a fase madura de sucessão, com o predomínio das secundárias tardias no dossel; já na área $\mathrm{B}$, ocorre o predomínio das secundárias iniciais no dossel e, nos outros estratos, há todos os grupos sucessionais presentes, resultando em um grande número de indivíduos e, na área $\mathrm{C}$, as pioneiras estão bem representadas em todos os estratos.

Com base na distribuição dos grupos sucessionais, a área $\mathrm{A}$ está em estágio maduro na sucessão, a área $\mathrm{B}$ em um estágio intermediário e, área $\mathrm{C}$, em estágio mais inicial.

Estratificação florestal e distribuição diamétrica $\mathrm{Na}$ área A, aproximadamente 64\% (204) dos indivíduos amostrados apresentam até $12 \mathrm{~m}$ de altura, 17\% (59 ind.) entre 12,1 e $20 \mathrm{~m}, 15 \%$ entre 20,1 e $28 \mathrm{~m}$ e $4 \%$ entre 28,1 e 36 m (21 ind.). Essa distribuição de indivíduos apresenta formato de "J invertido" (maior número de indivíduos nas menores classes de altura, diminuindo nas maiores classes). A grande concentração de indivíduos na primeira classe de altura deve-se pela abundância das espécies umbrófilas, principalmente $P$. suterella (figura 9).

Na área B, aproximadamente 59\% (238) dos indivíduos amostrados apresentam até $12 \mathrm{~m}$ de altura, 25\% (102 ind.) entre 12,1 e $20 \mathrm{~m}, 12 \%$ entre 20,1 e $28 \mathrm{~m}$. e $4 \%$ entre 28,1 e $36 \mathrm{~m}$ (59 ind.). Poucos indivíduos passam dos 30 metros de altura (figura 10).

Já na área C, aproximadamente 65\% (196) dos indivíduos amostrados apresentam até $12 \mathrm{~m}$ de altura, $28 \%$ ( 83 ind.) entre 12,1 e $20 \mathrm{~m}$. e 7\% (21 ind.) acima dos $20 \mathrm{~m}$. (figura 11). 


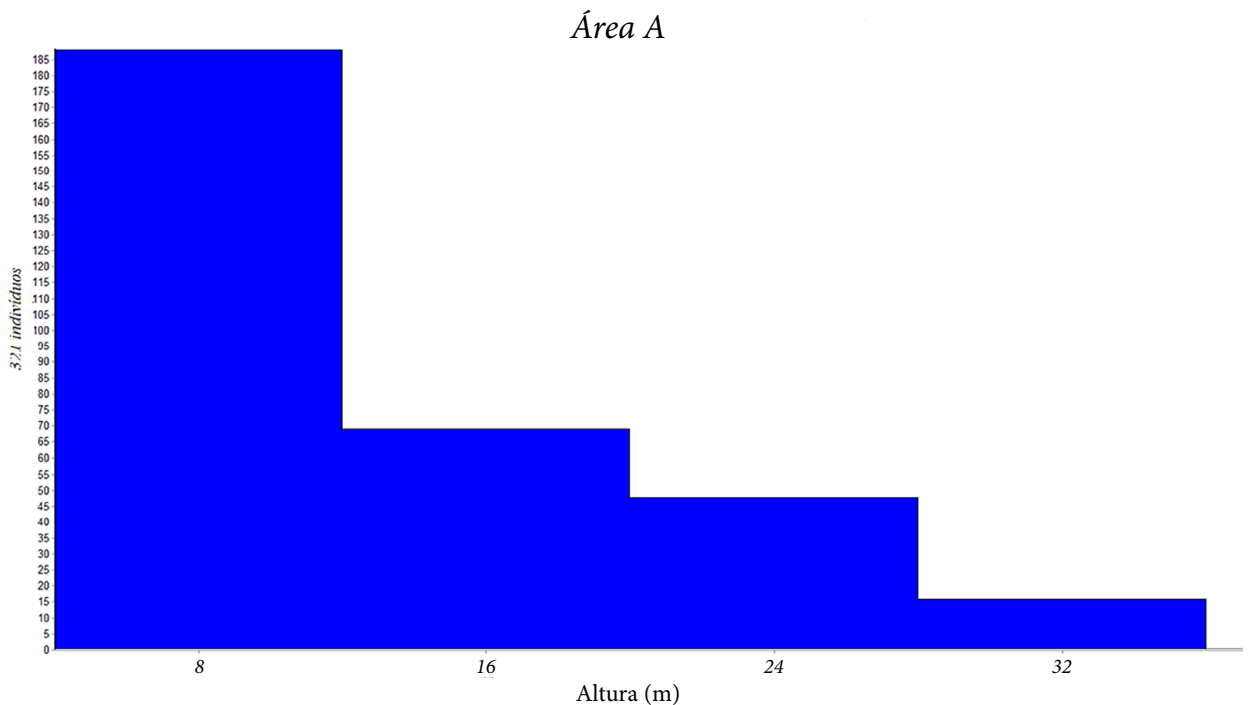

Figura 9. Distribuição dos indivíduos em classes de altura na área A, Parque Estadual da Cantareira, São Paulo, SP, Brasil. Figure 9. Distribution of individuals in height classes in area A, Parque Estadual da Cantareira, São Paulo, São Paulo State, Brasil.

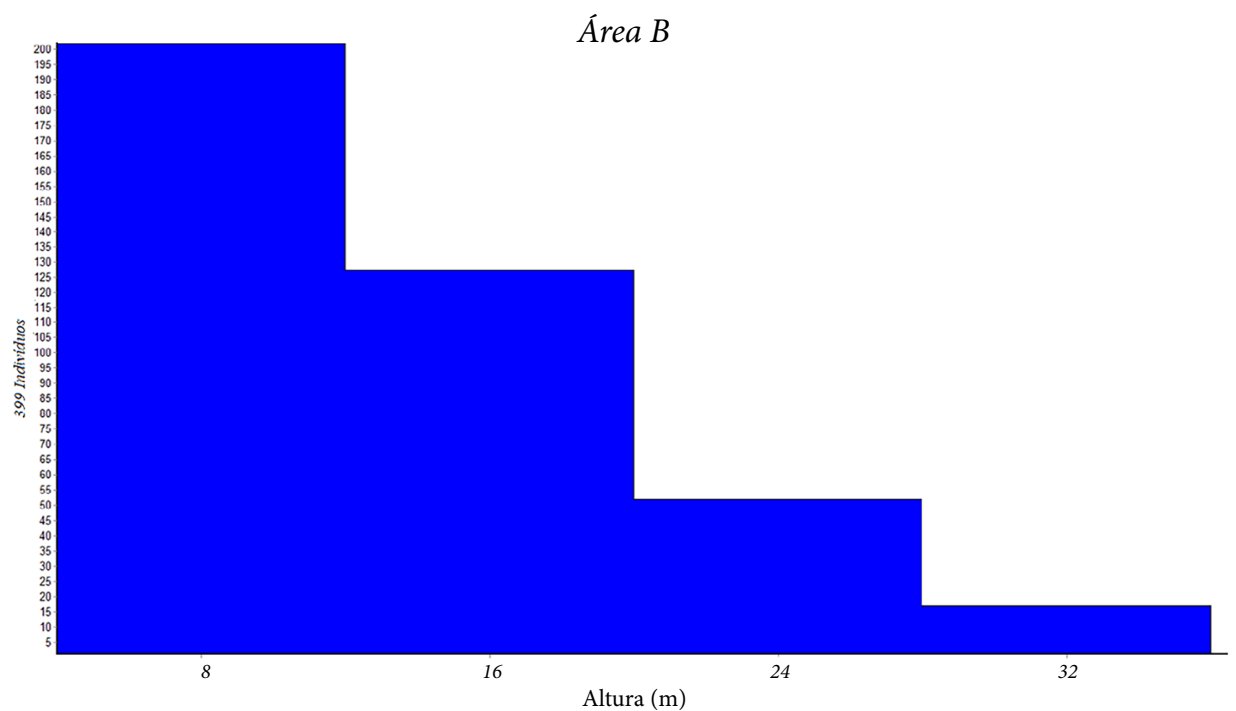

Figura 10. Distribuição dos indivíduos em classes de altura na área B, Parque Estadual da Cantareira, São Paulo, SP, Brasil. Figure 10. Distribution of individuals in height classes in area B, Parque Estadual da Cantareira, São Paulo, São Paulo State, Brasil.

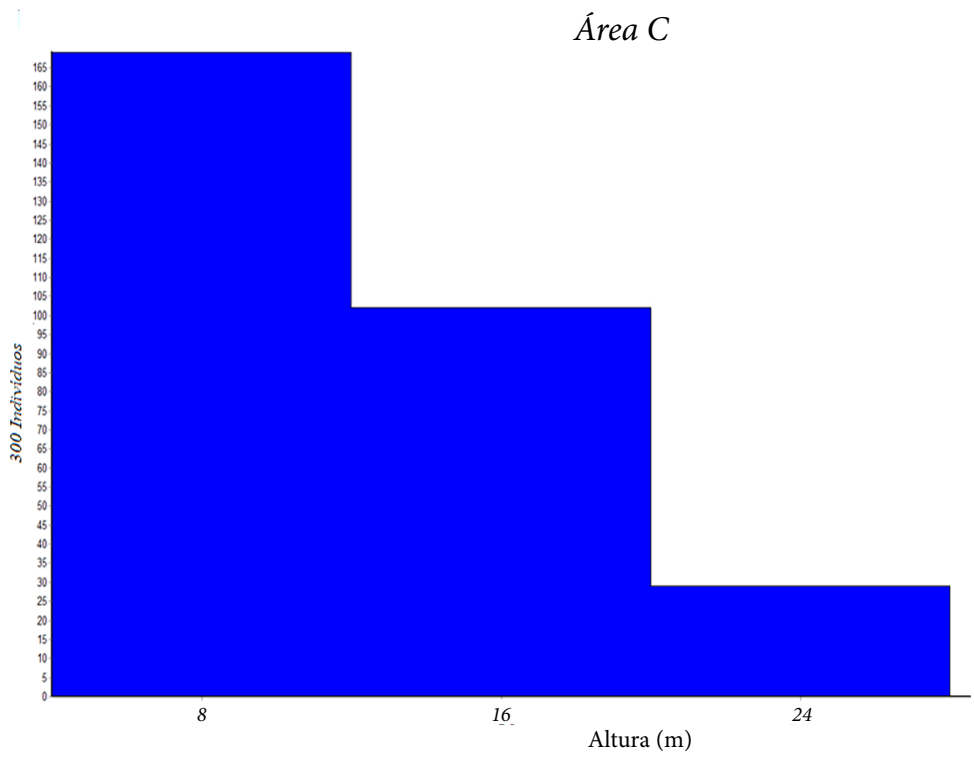

Figura 11. Distribuição dos indivíduos em classes de altura na área C, Parque Estadual da Cantareira, São Paulo, SP, Brasil. Figure 11. Distribution of individuals in height classes in area C, Parque Estadual da Cantareira, São Paulo, São Paulo State, Brasil. 
Ao compararmos as três áreas de estudo, quanto à distribuição das classes de altura, podemos constatar que as áreas A e B são similares quanto à porcentagem dos indivíduos nos diferentes estratos. Em ambas as áreas há predominância das secundárias tardias e iniciais nos diferentes estratos, com exceção do sub-bosque que em A possui exclusivamente espécies umbrófilas, enquanto em $\mathrm{B}$ ocorrem também indivíduos jovens de espécies secundárias. Por outro lado, na área $\mathrm{C}$, a porcentagem dos indivíduos na classe até $12 \mathrm{~m}$ de altura é bem menor em relação às áreas $\mathrm{A}$ e $\mathrm{B}$; as espécies pioneiras estão representadas em todos os estratos nesta área e, no sub-bosque há representantes de todas as categorias sucessionais.

Similaridade, agrupamento e ordenação entre as áreas de estudo - $\mathrm{Na}$ análise utilizando o coeficiente Canberra (UPGMA), as parcelas de um mesmo bloco mantêm-se de uma forma geral em um mesmo grupo, confirmando que as áreas de estudo (A, B e C) diferem entre si. No primeiro grupo, onde se encontram as parcelas da área $\mathrm{A}$, há somente uma única parcela (12) que pertence a B; porém o segundo e o terceiro grupos reconhecidos nesta análise reúnem exclusivamente parcelas das áreas $\mathrm{B}$ e $\mathrm{C}$ respectivamente (figura 12). O agrupamento da parcela 12 (área B) com as parcelas 1 a 10 (área $\mathrm{A}$ ), pode ser explicada como uma parcela cuja floresta está em fase madura de sucessão. É comum nas florestas ter trechos contíguos em fases distintas, podendo ser causadas pela presença de uma mancha mais antiga, clareiras ou efeitos de borda. As análises de ordenação e classificação destacam essas ocorrências.

$\mathrm{Na}$ análise de ordenação, utilizou-se a Análise de Correspondência (CA) e a matriz de número de indivíduos por espécie. Os eixos 1, 2 e 3 correspondem a 11,8, 8,5 e 6,1 por cento da inércia total encontrada, totalizando-se $26,4 \%$.
Podemos observar que as parcelas da área C estão separadas em todos os eixos (plano horizontal e vertical), sendo esta a mais diferente em relação às demais. As áreas A e B estão separadas mais no eixo 2 (plano horizontal), ou seja, em relação ao número de indivíduos, estão mais próximas, possivelmente devido às espécies tardias já estarem presentes nos estratos inferiores da área B (figuras 13 e 14).

Tanto as análises de classificação quanto as de ordenação mostram, de uma forma geral, a formação de três grupos que correspondem às três áreas de estudo, havendo maior proximidade entre as áreas $\mathrm{A}$ e $\mathrm{B}$ devido a uma maior presença das espécies tardias nessas áreas.

Síndrome de dispersão - As espécies zoocóricas destacaram-se em todas as áreas estudadas, A, B e C (85\%, 88\% e 70\%, respectivamente). As anemocóricas apresentaram valores mais altos na área $\mathrm{C}$, em virtude do maior número de pioneiras encontradas nesta última. Já as autocóricas estão em menor número na área B.

Espécies ameaçadas de extinção - Do total de 115 espécies identificadas neste estudo, conforme consta na tabela 4 , sete $(6,1 \%)$ enquadram-se em uma das categorias de grau de ameaça nas três listas consideradas. Ocotea catharinensis, presente nas três áreas de estudo, está classificada como vulnerável (VU) nas listas de São Paulo, do Brasil e IUCN; Cedrela fissilis, presente somente na área $\mathrm{B}$, é considerada VU nas listas de São Paulo e do Brasil, e em perigo (EN) na lista da IUCN; Trichilia silvatica, presente nas áreas A e B, e Eugenia prasina, na área B, são consideradas VU somente na lista da IUCN; Virola bicuhyba presente somente na área B, encontra-se EN nas listas de São Paulo e do Brasil; Pouteria bullata, presente somente na área B, é considerada EN na lista de São Paulo e Brasil e VU na lista da IUCN; E. cantareirae presente somente na área $\mathrm{A}$, na lista do Brasil está como EN e na lista de São Paulo era considerada extinta (EX).

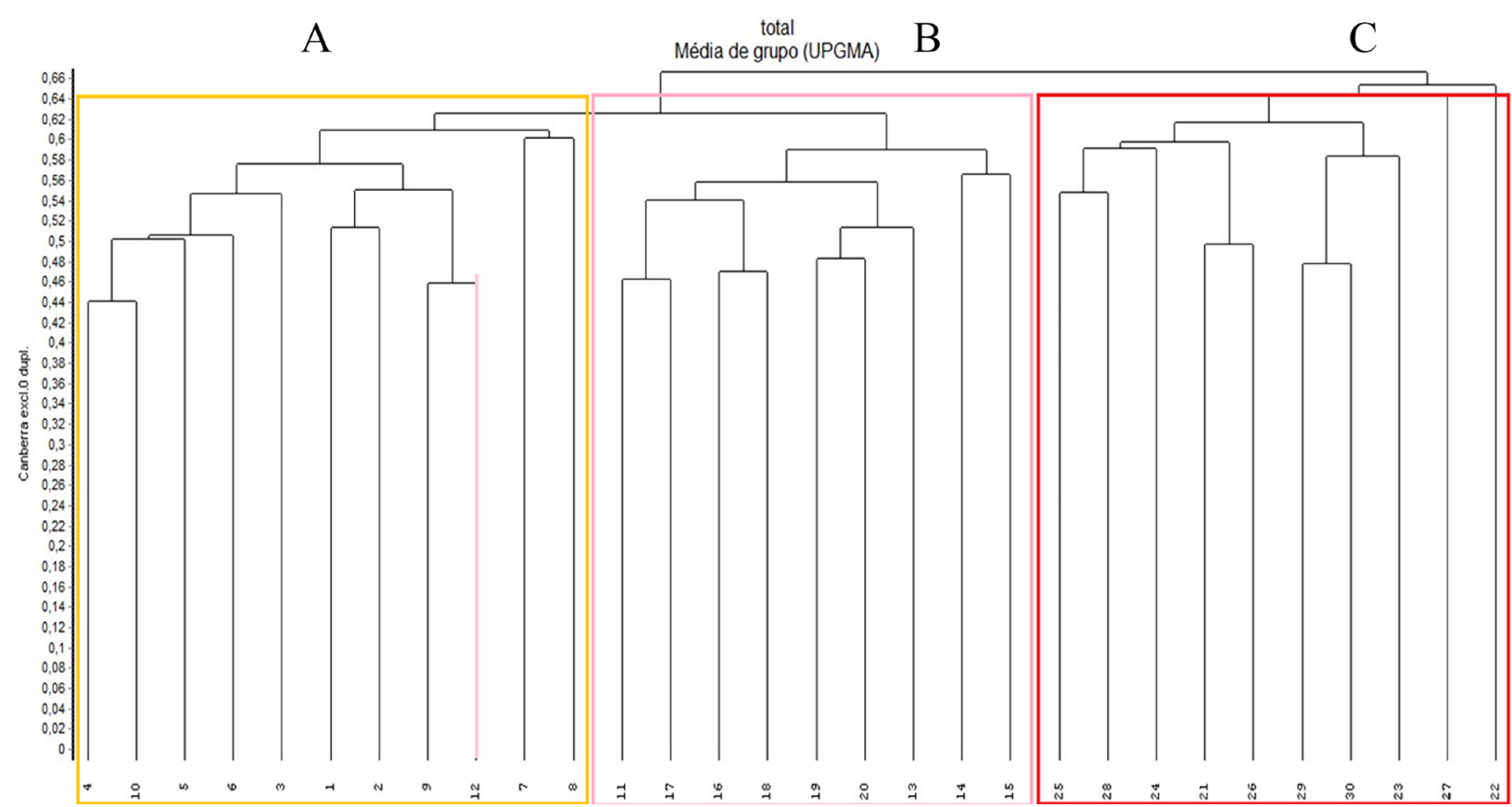

Figura 12. Análise de classificação das parcelas das três áreas de estudo, Parque Estadual da Cantareira, São Paulo, SP, Brasil., pelo método UPGMA e coeficiente Canberra. Coeficiente de correlação igual a 0,7821.

Figure 12. Analysis of classification of plots from the three studied areas, Parque Estadual da Cantareira, São Paulo, São Paulo State, Brasil., using the UPGMA method and the Canberra coefficient. Correlation coefficient equal to 0,7821 . 
Correspondência (CA) EIXOS 1 e 2

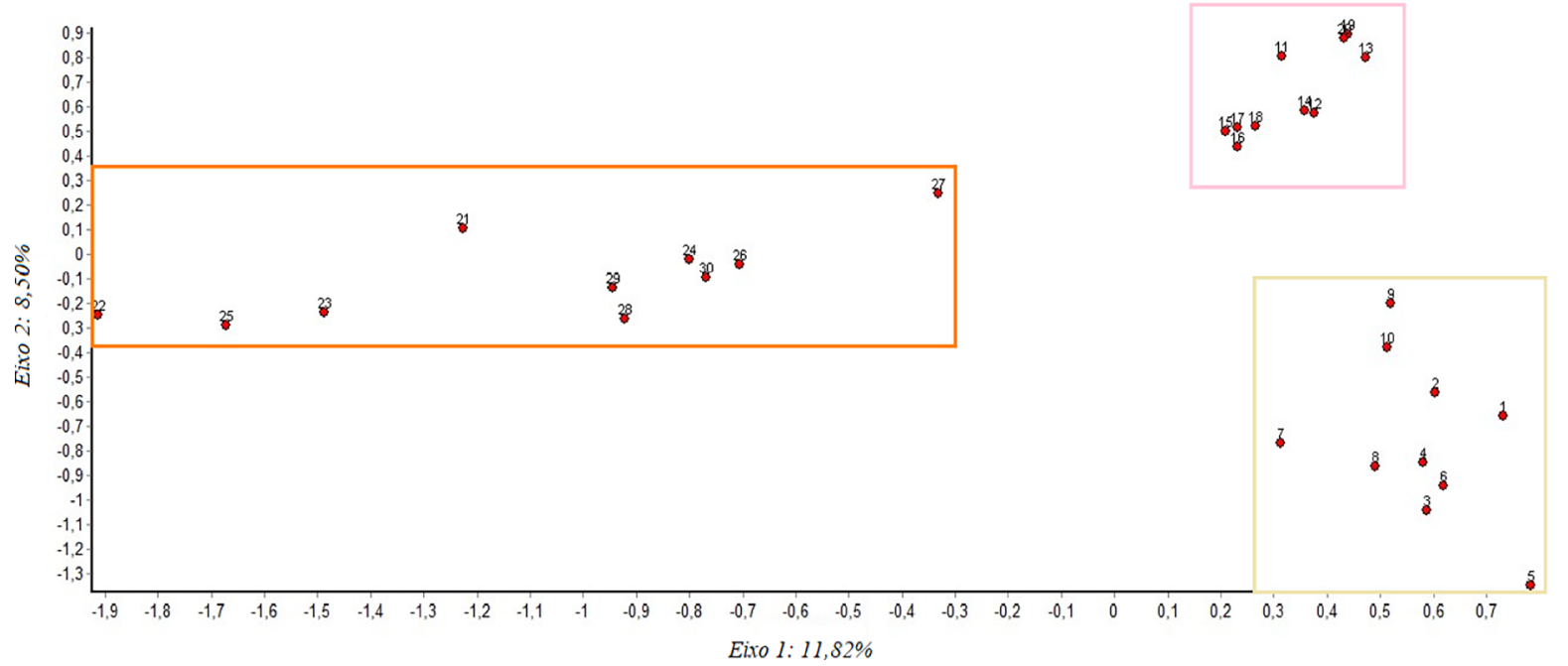

Figura 13. Eixos 1 e 2 da análise de ordenação pelo método CA das três áreas de estudo, Parque Estadual da Cantareira, São Paulo, SP, Brasil. Figure 13. Axes 1 and 2 of the ordering analyses by the CA method of the three study areas, Parque Estadual da Cantareira, São Paulo, São Paulo State, Brasil.

Correspondência (CA) ELXOS 1 e 3

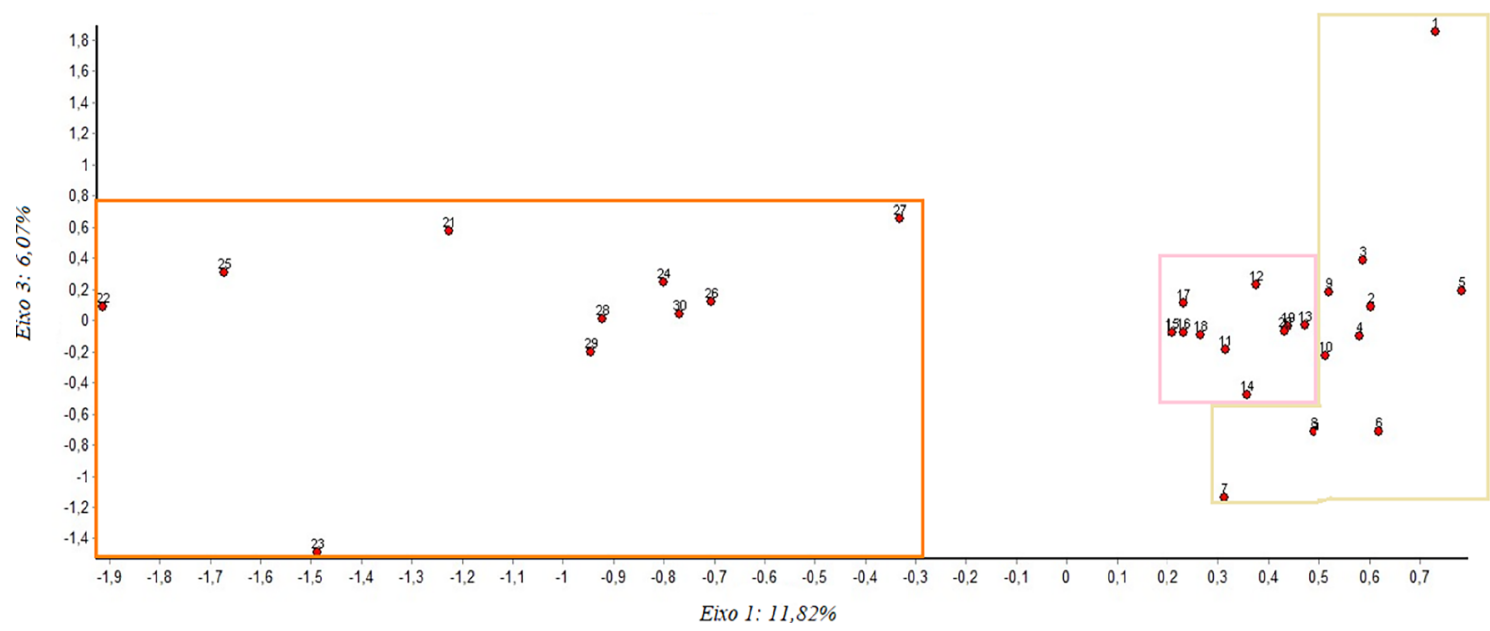

Figura 14. Eixos 1 e 3 da análise de ordenação pelo método CA das três áreas de estudo, Parque Estadual da Cantareira, São Paulo, SP, Brasil. Figure 14. Axes 1 and 3 of the ordering analyses by the CA method of the three study areas, Parque Estadual da Cantareira, São Paulo, São Paulo State, Brasil.

Tabela 4. Lista de espécies ameaçadas e sua classificação nas listas de São Paulo (2016), Brasil (2019c) e IUCN (2019). Categorias VU: Vulnerável, EN: Em perigo e EX: Extinta.

Table 4. List of threatened species and their classification in the lists of São Paulo, 2016, Brazil, 2019c and IUCN, 2019. VU categories: Vulnerable, EN: Endangered and EX: Extinct.

\begin{tabular}{lccc}
\hline \multirow{2}{*}{ Espécie } & & Listas & \\
\cline { 2 - 4 } & São Paulo & Brasil & IUCN \\
\hline Ocotea catharinensis Mez & $\mathrm{VU}$ & $\mathrm{VU}$ & $\mathrm{VU}$ \\
Cedrela fissilis Vell. & $\mathrm{VU}$ & $\mathrm{VU}$ & $\mathrm{EN}$ \\
Trichilia silvatica C.DC. & - & - & $\mathrm{VU}$ \\
Virola bicuhyba (Schott ex Spreng.) Warb. & $\mathrm{EN}$ & $\mathrm{EN}$ & - \\
Eugenia prasina O.Berg & - & - & $\mathrm{VU}$ \\
Euplassa cantareirae Sleumer & $\mathrm{EX}$ & $\mathrm{EN}$ & - \\
Pouteria bullata (S.Moore) Baehni & $\mathrm{EN}$ & $\mathrm{EN}$ & $\mathrm{VU}$ \\
\hline
\end{tabular}




\section{Discussão}

Composição Florística - As famílias Myrtaceae e Lauraceae também foram as mais ricas em outros estudos realizados na Floresta Ombrófila Densa Montana no Estado de São Paulo por Baitello et al. (1993), Garcia \& Pirani (2001), Catharino et al. (2006), Alves \& Metzger (2006), Ogata \& Gomes (2006), Lima et al. (2011), Arzolla (2002, 2011) e Barretto (2013), trabalhos realizados no município de São Paulo e arredores, e no interior do Estado, por Ivanauskas (1997), Aguiar et al. (2001), Sztutman \& Rodrigues (2002) e Moura \& Mantovani (2017), sendo que neste último estudo somente Myrtaceae destacou-se pela sua riqueza.

Os gêneros Cinnamomum, Eugenia, Mollinedia, Myrcia e Ocotea também se destacaram em outros levantamentos realizados no PEC por Arzolla (2002, 2011), Nectandra também se destacou no levantamento realizado no PEC por Arzolla (2002), Eugenia, Myrcia e Ocotea, por Catharino et al. (2006), Lima et al. (2011) e Barretto (2013) em remanescentes de Floresta Ombrófila Densa Montana situados na região metropolitana de São Paulo, Eugenia e Ocotea, por Aguiar et al. (2001) na região de Cunha e somente Eugenia por Moura \& Mantovani (2017) no município de Miracatu.

Parâmetros fitossociológicos - Os valores totais, desde estudo, de densidade absoluta de 1700 ind. ha ${ }^{-1}$ e dominância absoluta de $39,8 \mathrm{~m}^{2}$ ha $^{-1}$ são compatíveis com os encontrados em outros trechos do PEC (Baitello et al. 1993, Arzolla 2002), onde a densidade absoluta variou entre 1248 a 2295 ind./ha e a dominância entre 35,7 a 48,4 m² $\mathrm{ha}^{-1}$. Em estudo realizado em São Paulo e nos municípios vizinhos de Cotia e Itapevi (Barretto 2013) os valores de densidade variaram entre 1425 a 1760 ind. ha ${ }^{-1}$ e de dominância entre 44,5 a 49,3 $\mathrm{m}^{2} \mathrm{ha}^{-1}$, também compatíveis com os do presente estudo.

Em outros trechos da floresta do PEC estudados por Arzolla (2002), também foram encontradas $H$. silvianii e A. olivaceum entre as espécies mais dominantes, e em Itapevi, somente $H$. silvianii (Barretto 2013). Klein (1990) destaca A. olivaceum como uma das espécies mais importantes nas encostas das Serras do Sul do país e cita que $E$. cantareirae está associada a florestas em sucessão avançada. Sendo que esta também se destacou no estudo realizado no PEC por Baitello et al. (1993). Ainda, Blum \& Roderjan (2007) citam a E. cantareirae como espécie indicadora de formação de Floresta Ombrófila Densa Montana.

A espécie $P$. suterella também se destacou em outros fragmentos do PEC (Arzolla 2002) e na Floresta Ombrófila Densa Montana das encostas de Paranapiacaba (Lima et al. 2011), sendo que Bertani (2006) relata que essa espécie frequentemente se destaca pelo seu valor de densidade nos fragmentos florestais do Estado de São Paulo.

A. triplinervia, H. silvianii, C. canjerana, C. obliqua e P. floribundum destacaram-se por seus valores de dominância em outros trechos do PEC (Arzolla 2002). Em alguns levantamentos realizados no Estado de São Paulo, A. triplinervia destacou-se pelo seu valor de importância (Ivanauskas 1997, Arzolla 2002, Barretto 2013).
Esta espécie ocorre somente na forma de indivíduos mais velhos nas florestas mais maduras, geralmente esparsos, sendo, por isso, rara, pois não se vê na regeneração (Klein 1984, 1990). Na área de estudo, não foram observados indivíduos jovens desta espécie. No levantamento realizado por Catharino et al. (2006), dentre essas espécies, somente C. obliqua também se destaca.

C. oblongifolia destacou-se nos levantamentos de Arzolla (2002, 2011) e Barretto (2013). Em outro trecho estudado por Arzolla (2011), C. floribundus e A. triplinervia também se destacaram. Piptocarpha macropoda também foi encontrada em alta frequência em trecho do PEC (Arzolla 2011) e no levantamento feito por Moura \& Mantovani (2017) na Floresta Ombrófila Densa do Vale do Ribeira

Análises grupos ecológicos - No estudo realizado por Barretto (2013), em seu levantamento geral de espécies tardias, a percentagem apresentou o dobro do que encontrado neste estudo. Mas essa diferença pode ser pelo fato de que o autor considerou as espécies umbrófilas como parte das secundárias tardias.

Em outro estudo realizado no PEC por Arzolla (2002), as tardias destacaram-se três vezes a mais que as iniciais, mas lembrando que o autor considerou também naquele trabalho, assim como Barretto, as umbrófilas como parte das espécies tardias.

O trabalho realizado por Gandolfi et al. (1995) encontrou $30 \%$ de espécies pioneiras, sugerindo que o trecho estudado pelo autor se encontrava numa condição inicial em termos sucessionais. Nos estudos de Arzolla (2011) e Moura \& Mantovani (2017), as pioneiras também obtiveram percentagem expressivas $(61 \%$ e $26 \%$, respectivamente), mas os trechos referem-se a áreas de regeneração.

Barretto (2013), em suas análises, constatou nas três áreas estudadas por ele, em fase madura de sucessão, alta dominância e riqueza das espécies secundárias tardias, assim como observado na área A deste estudo.

Síndrome de dispersão - Em outros levantamentos realizados na Floresta Ombrófila Densa por Catharino et al. (2006), Lima et al. (2011), Barretto (2013), Moura \& Mantovani (2017) foram encontrados resultados semelhantes quanto à porcentagem de espécies zoocóricas. Lima et al. (2011) relata que nas áreas que desenvolveu seu estudo predominam espécies zoocóricas, sendo áreas maduras da Floresta Ombrófila Densa Montana das encostas da Serra do Mar em Santo André, e Mantovani (1998) relata que é comum a predominância de espécies zoocóricas nessa formação florestal.

Espécies ameaçadas de extinção - A espécie $E$. cantareirae foi classificada como vulnerável (VU) no estudo realizado por Souza et al. (2016), o que diverge com a lista atualizada de flora ameaçada do Estado de São Paulo, publicada no Diário Oficial de São Paulo Poder Executivo - Seção I - de 07 de junho de 2016, na qual consta como extinta (EX). Essa espécie é considerada rara, no entanto tal classificação para São Paulo necessita ser revista. A presença dessas espécies mostra a importância de se conservar e cuidar desse remanescente florestal. 


\section{Conclusões}

Dentre as conclusões deste estudo, podemos constatar que as três áreas analisadas são floristicamente e estruturalmente diferentes, pois algumas das espécies amostradas estão presentes em todas as áreas e outras são exclusivas de apenas uma ou duas delas e mesmo quando presentes nas três áreas, não apresentam o mesmo VI em cada uma delas.

Todos os grupos sucessionais (pioneiras, secundárias iniciais e tardias e umbrófilas) estão presentes nas três áreas, porém em proporções distintas e também diversas em cada um de seus estratos componentes.

Na área A, em seu dossel, há predominância de espécies secundárias tardias; estrato médio com secundárias iniciais e o sub-bosque, majoritariamente, formado por espécies umbrófilas. Esta área ainda contem baixa representatividade de espécies pioneiras e secundárias iniciais que ocorrem em pequenas clareiras e bordas da mancha estudada.

$\mathrm{Na}$ área $\mathrm{B}$, as espécies secundárias iniciais predominam tanto no dossel quanto no estrato médio da floresta e o subbosque é formado por todos os grupos sucessionais, exceto as pioneiras, estas com baixa representatividade e, quando presentes, estão restritas a pequenas clareiras, o mesmo que ocorre na área $\mathrm{A}$.

$\mathrm{A}$ área $\mathrm{C}$ possui dossel descontínuo com predomínio de pioneiras; o estrato médio apresenta predomínio de pioneiras e iniciais, com poucas tardias e umbrófilas. As clareiras dessa área são maiores que em A e B.

Conclui-se, pela análise, que a área $\mathrm{A}$ está em fase madura, a área $\mathrm{B}$ em fase intermediária e, a $\mathrm{C}$, em uma fase mais inicial que as anteriores.

Avaliar o estágio successional de uma determinada área é um grande desafio científico, com importantes implicações na conservação. Conhecer a floresta em diferentes estágios traz subsídios a medidas aplicadas visando a recuperação, não somente do Parque Estadual da Cantareira, como da Serra da Cantareira e demais áreas da Floresta Ombrófila Densa Montana. A floresta do Parque Estadual da Cantareira, especificamente no Núcleo Pedra Grande, apesar de haver sofrido grande pressão antrópica, ainda abriga remanescentes florestais preservados, dos quais a área A é um exemplo, que servem como fonte de sementes e outras unidades de dispersão para a recuperação natural de trechos em estágio sucessional intermediário a inicial, como as áreas $\mathrm{B}$ e $\mathrm{C}$ do presente estudo.

Estudos sobre sucessão natural da vegetação nativa em florestas do Planalto Paulista além de serem escassos, são de grande importância para garantir às gerações futuras a manutenção dos serviços ecossistêmicos da Mata Atlântica, hoje ainda bastante afetada pela fragmentação e consequente perda de biodiversidade.

\section{Agradecimentos}

Agradecemos ao Conselho Nacional de Desenvolvimento Científico e Tecnológico, pela Bolsa de Mestrado concedida à primeira Autora (Processo $n^{\circ} 133843 / 2018-9$ ) junto ao Programa de Pós-Graduação em Biodiversidade Vegetal e Meio Ambiente do Instituto de Botânica de São Paulo e bolsa de produtividadade de Inês Cordeiro, Processo 311275/2019-2.
Ao Instituto Florestal pelo apoio e estrutura para a realização do trabalho. Ao P.E. da Cantareira pelo apoio recebido.

\section{Contribuição dos autores}

Rafaela Dias Valeck da Silva: Responsável pelo planejamento, pela instalação do trabalho, pela coleta de dados em campo, pelas análises de dados e elaboração do manuscrito.

Inês Cordeiro: Contribuição no planejamento, na análise de dados e na redação do manuscrito.

Frederico Alexandre Roccia Dal Pozzo Arzolla: Contribuição no planejamento, na instalação do trabalho, na coleta de dados em campo, nas análises de dados e na redação do manuscrito.

\section{Conflitos de interesse}

Não há conflitos de interesse.

\section{Literatura Citada}

Aguiar, O.T., Pastore, J.A., Rocha, F.T., Baitello, J.B. 2001. Flora fanerogâmica de um trecho da Floresta Densa Secundária do Parque Estadual da Serra do Mar-Núcleo Cunha Indaiá - SP. Disponível em https://smastr16.blob. core.windows.net/iflorestal/ifref/RIF13-1/RIF13-1_1-18. pdf (acesso em 18-V-2020).

Alves, L.F. \& Metzger, J.P. 2006. A regeneração florestal em áreas de floresta secundária na Reserva Florestal do Morro Grande, Cotia, SP. Biota Neotropica 6(2). Disponível em http://biotaneotropica.org.br/v6n2/pt/ abstract?article+bn00406022006/ (acesso em 18-V-2020).

APG - Angiosperm Phylogeny Group. 2016. An update of the Angiosperm Phylogeny Group Classification for the orders and families of flowering plants: APG IV. Botanical Journal of the Linnean Society 181: 1-20.

Aragaki, S. 1997. Florística e estrutura de trecho remanescente de floresta no Planalto Paulistano (SP). São Paulo: Dissertação de Mestrado, Universidade de São Paulo, São Paulo.

Arzolla, F.A.R.D.P. 2002. Florística e Fitossociologia de Trecho da Serra da Cantareira, Núcleo Águas Claras, Parque Estadual da Cantareira, Mairiporã - SP. Dissertação de Mestrado, Universidade Estadual de Campinas, Campinas.

Arzolla, F.A.R.D.P. 2011. Florestas secundárias e a regeneração natural de clareiras antrópicas na Serra da Cantareira, SP. Tese de Doutorado, Universidade Estadual de Campinas, Campinas.

Ayres, N.C.M. 2006. O ciclo da Caapora: Uma história de relação entre a RMSP e o Parque Estadual da Cantareira (1963 - 2005). São Paulo. Dissertação de Mestrado, Universidade Católica de São Paulo. São Paulo.

Baitello, J.B., Aguiar, O.T., Rocha, F.T., Pastore, J.A., Esteves, R. 1993. Estrutura Fitossociológica da Vegetação Arbórea da Serra da Cantareira (SP) - Núcleo Pinheirinho. Revista do Instituto Florestal 5 (2): 133-161. 
Barbosa, L.M. 2017. Lista de espécies indicadas para restauração ecológica para diversas regiões do Estado de São Paulo. Relatório Técnico, Secretaria do Meio Ambiente de São Paulo.

Barretto, E.H.P. 2013. Florestas climácicas da região metropolitana de São Paulo - SP: caracterização florística, estrutural e relações fitogeográficas. São Paulo: Dissertação de Mestrado, Instituto de Botânica, São Paulo.

Bernacci, L.C. \& Leitão Filho, H.F. 1996. Flora fanerogâmica da floresta da Fazenda São Vicente, Campinas, SP. Revista Brasileira de Botânica, 19: 149-164.

Bertani, D. F. 2006. Ecologia de populações de Psychotria suterella Müll. Arg. (Rubiaceae) em uma paisagem fragmentada de Mata Atlântica. Tese de Doutorado, Universidade Estadual de Campinas, Campinas.

Blum, C.T. \& Roderjan, C.V. 2007. Espécies indicadoras em um gradiente da Floresta Ombrófila na Serra da Prata, Paraná, Brasil. Revista Brasileira de Biociências 5(2): 873-875.

Brancalion, H.S., Galdolfi, S., Rodrigues, R. R. 2015. Restauração Florestal. Oficina de Textos, São Paulo.

Brasil. Ministério do Meio Ambiente. Lista Nacional Oficial de Espécies da Flora Ameaçadas de

Budowski, G. 1965. Distribution of tropical rain forest species in the light of sucessional processes. Turrialba 15(1): 40-42.

Catharino, E.L., Bernacci, L.C., Franco, G.A.D.C., Durigan, G., Metzger, J.P. 2006. Aspectos da composição e diversidade do componente arbóreo das florestas da Reserva Florestal do Morro Grande, Cotia, SP. Biota Neotropica 6(2). Disponível em http://biotaneotropica. org.br/v6n2/pt/abstract?article+bn00306022006/ (acesso em 18-V-2020).

Clements, F.E. 1916. Plant succession: Na analysis of the development of vegetation. BHL: Biodiversity Heritage Library. Disponível em www.biodversitylibrary.org/ (acesso em 18-V-2020).

Denslow, J.S. 1980. Gap partitioning among tropical rainforest trees. Biotropica 12: 47-51.

Extinção. Portaria MMA n ${ }^{\circ} 443$, de 17 de dezembro de 2014. Disponivel em http://cncflora.jbrj.gov.br/portal/ static/pdf/portaria_mma_443_2014.pdf (acesso em 18-V-2020).

Farinaci, J.S. \& Batistella, E.M. 2012. Variação na cobertura vegetal nativa em São Paulo: Um panorama do conhecimento atual. Revista Árvore 36(4): 695-705, 2012.

Flora do Brasil 2020 em construção. Jardim Botânico do Rio de Janeiro. Disponível em (http://floradobrasil. jbrj.gov.br/reflora/floradobrasil/FB10964) (acesso em 11-III-2020).

Fundação SOS Mata Atlântica - Aqui tem Mata. Disponível em (http://aquitemmata.org.br/\#/busca/ sp/S\%C3\%A3o\%20Paulo/S\%C3\%A3o\%20Paulo) (acesso em 26-I-2020).

Gandolfi, F. 1991. Estudo florístico e fitossociológico de uma floresta residual na área do Aeroporto Internacional de São Paulo, Município de Guarulhos, SP. Dissertação de Mestrado, Universidade Estadual de Campinas, Campinas.
Gandolfi, F., Leitão-Filho, H.F., Bezerra, C.L.F. 1995. Levantamento florístico e caráter sucessional das espécies arbustivo-arbóreas de uma floresta mesófila semidecidua no município de Guarulhos, SP. Revista Brasileira Biologia 55(4): 753-767.

Garcia, R.J.F. \& Pirani, J.R. 2001. Estudo florístico dos componentes arbóreos e arbustivo da mata do Parque Santo Dias, São Paulo, SP, Brasil. Boletim de Botânica Universidade de São Paulo 19: 15-42.

Gómez-Pompa, A. 1971. Posible papel de la vegetación secundaria en la evolución de la flora tropical. Biotropica 3: 125-135.

IBGE. 2012. Fundação Instituto Brasileiro de geografia e Estatística. Manual técnico da vegetação brasileira. $2^{\text {ed }}$, Rio de Janeiro.

IBGE. Fundação Instituto Brasileiro de Geografia e Estatística. Disponível em http://7a12.ibge.gov.br/ vamos-conhecer-o-brasil/nosso-territorio/biomas.html (acesso em 16-XI-2019).

Ivanauskas, N. M. 1997. Caracterização florística e fisionômica da Floresta Atlântica sobre a formação Pariquera-Açu, na Zona da Morraria Costeira do Estado de São Paulo. Dissertação de Mestrado, Universidade Estadual de Campinas, Campinas.

Kageyama, P.Y. \& Castro, C.F.A. 1989. Sucessão secundária, Estrutura genética e Plantações de espécies arbóreas nativas. Instituto de Pesquisas e Estudos Florestais 41/42: 83-93.

Klein, R.M. 1984. Aspectos Dinâmicos da Vegetação do Sul do Brasil. Sellowia 36: 5-54.

Klein, R.M. 1990. Estrutura, composição florística, dinamismo e manejo da Mata Atlântica (Floresta Ombrófila Densa) do Sul do Brasil. In: Simpósio de Ecossistemas da Costa Sul e Sudeste Brasileira: Estrutura, funções e manejo, 2 Águas de Lindóia, 1990. Anais... Academia de Ciências do Estado de São Paulo. pp. 259-286.

Köppen, G. Classificação Climática de KoppenGeiser. Disponível em https://portais.ufg.br/up/68/o/ Classifica_o_Clim_tica_Koppen.pdf (acesso em 17-XI-2019).

Leitão-Filho, H.F. 1987. Considerações sobre a florística de florestas tropicais e sub-tropicais do Brasil. IPEF 45: 41-46.

Leite, M. 2007. Nos caminhos da Biodiversidade Paulista / Nas Costas do Brasil. Os litorais paulistas. São Paulo: Secretaria do Meio Ambiente: Instituto Amigos da Reserva da Biosfera da Mata Atlântica: Imprensa oficial do Estado de São Paulo.

Lima, M.E.L., Cordeiro, I., Moreno, P.R.H. 2011. Estrutura do componente arbóreo em Floresta Ombrófila Densa Montana no Parque Natural Municipal Nascentes de Paranapiacaba (PNMNP), Santo André, SP, Brasil. Hoehnea 38(1): 73-96.

Lino, C.F. \& Amaral, M.M. 2018. Mata Atlântica e Sociobiodiversidade: Desafios e caminhos para a sustentabilidade. CN-RBMA Conselho Nacional da Reserva da Biosfera da Mata Atlântica. São Paulo: IA- RBMA. 
Mantovani, W. 1998. Dinâmica da Floresta Pluvial Atlântica. Anais do IV Simpósio de Ecossistemas Brasileiros. Praia, Represa e Mata - Águas de Lindóia. ACIESP 104 v. II.

Moura, C. \& Mantovani, W. 2017. Regeneração natural da Floresta Ombrófila Densa após oito anos de abandono de atividades agrícolas em Miracatú, Vale do Ribeira, SP. Revista do Instituto Florestal 29(1): 91-119.

Mueller-Dombois, D. \& Ellenberg, H. 1974. Aims and methods of vegetation ecology. New York: John Wiley $\&$ Sons.

Myers, N., Mittermeier, R.A., Mittermeier, C.G., Fonseca, G.A.B. 2000. Kent, J. Biodiversity hotspots for conservation priorities. Nature 403: 853-845.

Ogata, R. \& Gomes, E.P.C. Estrutura e composição da vegetação no Parque CEMUCAM, Cotia, SP. Hoehnea 33(3): 371-384.

Polisel, R.T. \& Franco, G.A.D.C. 2007. Caracterização sucessional de uma floresta secundária com 40 anos de idade em Juquitiba, SP. Revista Brasileira de Biociências 5(supl. 2): 387-389.

Rocha, A.A. \& Costa, J.P.O. 1998. A Reserva da Biosfera da Mata Attântica e sua aplicação no Estado de São Paulo: apresentação Covas, M.; prefácio Feldmann, F. J. - São Paulo: Terra Virgem, Secretaria do Meio Ambiente do Estado de São Paulo.

Rodrigues, R.R. \& Shepherd, G.J. 1992. Análise da variação estrutural e fisionômica da vegetação e características edáficas, num gradiente altitudinal na Serra do Japi. In: L.P.C. Morellato (org.). História natural da Serra do Japi: ecologia e preservação de uma área florestal no sudeste do Brasil. Editora Unicamp: Campinas, pp. 64-96.
São Paulo. 2010. Secretaria do Meio Ambiente. Plano de Manejo do Parque Estadual da Cantareira. São Paulo: Fundação Florestal.

São Paulo. 2016. Resolução SMA n ${ }^{\circ}$ 057, de 05 de junho de 2016. Publica a segunda revisão da lista oficial das espécies da flora ameaçadas de extinção no Estado de São Paulo. Diário Oficial do Estado de São Paulo, de 30/06/2016, Seção 1, pp. 55-57.

Shepherd, G. J. 2010. Fitopac 2.1. Manual do usuário. Campinas: UNICAMP.

Souza, S.C.P.M., Silva, A.G., Franco, G.A.D.C., Ivanauskas, N.M. 2016. A vegetação secundária em um fragmento florestal urbano: Influência de exóticas invasoras na comunidade vegetal. Revista do Instituto Florestal 28(1): 7-35.

Swaine, M.D. \& Whitmore, T.C. 1988. On the definition of ecological species groups in tropical rain forests. Vegetation 75: 81-86.

Sztutman, M. \& Rodrigues, R.R. 2002. O mosaico vegetacional numa área de floresta contínua da planície litorânea, Parque Estadual da Campina do Encantado, Pariquera-Açu, SP. Revista Brasileira de Botânica 25(2): 161-176.

Tabarelli, M. 1994. Clareiras naturais e a dinâmica sucessional de um trecho de floresta na Serra da Cantareira, SP. Dissertação Mestrado, Universidade de São Paulo, São Paulo.

Whitmore, T.C. 1989. Canopy gaps and the major groups of florest trees. Ecology 70(3): 536-538.

Submissão: $13 / 10 / 2020$

Aceite: $03 / 11 / 2021$

Editora Associada: Cláudia Baider 